\title{
Recent Advances of Film-Forming Kinetics in Organic Solar Cells
}

\author{
Qiuju Liang ${ }^{1}$, Jianhong Yao ${ }^{1}$, Zhangbo Hu ${ }^{1}$, Puxin Wei ${ }^{2}$, Haodong Lu ${ }^{1}$, Yukai Yin ${ }^{2}$, Kang Wang ${ }^{2}$ and \\ Jiangang Liu ${ }^{2, *}$
}

check for updates

Citation: Liang, Q.; Yao, J.; Hu, Z.; Wei, P.; Lu, H.; Yin, Y.; Wang, K.; Liu, J. Recent Advances of Film-Forming Kinetics in Organic Solar Cells. Energies 2021, 14, 7604. https:// doi.org/10.3390/en14227604

Academic Editor: Bashir A. Arima

Received: 1 October 2021

Accepted: 8 November 2021

Published: 14 November 2021

Publisher's Note: MDPI stays neutral with regard to jurisdictional claims in published maps and institutional affiliations.

Copyright: (c) 2021 by the authors. Licensee MDPI, Basel, Switzerland. This article is an open access article distributed under the terms and conditions of the Creative Commons Attribution (CC BY) license (https:// creativecommons.org/licenses/by/ $4.0 /)$.
1 School of Microelectronics, Northwestern Polytechnical University, Xi'an 710129, China; qiujuliang@nwpu.edu.cn (Q.L.); soblack@mail.nwpu.edu.cn (J.Y.); huzb@mail.nwpu.edu.cn (Z.H.); HaodongLu@mail.nwpu.edu.cn (H.L.)

2 School of Electronics and Information, Northwestern Polytechnical University, Xi'an 710129, China; pxwei@mail.nwpu.edu.cn (P.W.); ykyin@mail.nwpu.edu.cn (Y.Y.); kangwang@mail.nwpu.edu.cn (K.W.)

* Correspondence: jgliu@nwpu.edu.cn

\begin{abstract}
Solution-processed organic solar cells (OSC) have been explored widely due to their low cost and convenience, and impressive power conversion efficiencies (PCEs) which have surpassed $18 \%$. In particular, the optimization of film morphology, including the phase separation structure and crystallinity degree of donor and acceptor domains, is crucially important to the improvement in PCE. Considering that the film morphology optimization of many blends can be achieved by regulating the film-forming process, it is necessary to take note of the employment of solvents and additives used during film processing, as well as the film-forming conditions. Herein, we summarize the recent investigations about thin films and expect to give some guidance for its prospective progress. The different film morphologies are discussed in detail to reveal the relationship between the morphology and device performance. Then, the principle of morphology regulating is concluded with. Finally, a future controlling of the film morphology and development is briefly outlined, which may provide some guidance for further optimizing the device performance.
\end{abstract}

Keywords: organic solar cells; solution process; morphology; film-forming kinetics

\section{Introduction}

Organic solar cells (OSCs) have been recognized as one of the most promising green devices to convert solar energy to electricity, which possesses the advantages of light weight, flexibility, processable printing and large-area production [1-4]. OSCs consist of an anode, cathode and active layer. By 2021, thanks to the favorable development of donor and acceptor materials, optimization of active layer morphology and maturity of processing technology, the OSCs have realized outstanding power conversion efficiency (PCE), over $18 \%$ for binary devices [5-12]. These devices based on a ternary active layer can achieve the same or better performance [13-19].

The performance of OSC devices is closely related to the morphology of the active layer, because it crucially affects the photophysical conversion process. The photophysical conversion process usually includes photon absorption (exciton generation), exciton diffusion, exciton separation, carrier transport and collection [20]. After the active layer absorbs a photon, the electron in the donor's highest occupied molecular orbital (HOMO) is excited and jumps to the donor's lowest unoccupied molecular orbital (LUMO) to form an electron-hole pair bounded by coulomb forces. Because of the strong binding energy $(0.35 \sim 0.5 \mathrm{eV})$, the exciton cannot be separated through thermal vibration [21,22]. Therefore, the exciton separation can only rely on the electric field gravity provided by the built-in electric field at the donor/acceptor (D/A) interfaces. However, if the domain size is too large, some excitons cannot reach the D/A interfaces due to their short lifetime $[23,24]$. Only the excitons near the D/A interface $(5 \sim 10 \mathrm{~nm})$ can reach the interfaces and have the 
chance to dissociate into electrons and holes driven by the built-in electric field. Therefore, the suitable domain size is usually 10 20 nm in OSCs [25,26]. According to previous research, the molecular orientation of the donor and acceptor at the interface directly determines the driving forces of the built-in electric field [27]. When the orientation of the donor and acceptor is consistent, the coupling force between the donor and acceptor is large, leading to a strong built-in electric field, which is beneficial for exciton dissociation [28-30]. Furthermore, generated free electrons and holes need to transport to the corresponding anode and cathode through the pure acceptor and donor phases, respectively. Hence, the bi-continuous separated donor and acceptor phases, i.e., an interpenetrating network structure (Figure 1), is highly desirable for carrier transmission [31-35]. In addition, high carrier mobility ensures the efficiency of charge collection, hence a high crystallinity degree of the donor and acceptor is required because it reduces the energy barrier of charge transport and helps to obtain high carrier mobility [36-41]. Additionally, the donor and acceptor should be enriched at the anode and cathode, respectively, which can effectively reduce the bimolecular recombination, thereby improving the charge collection [42]. According to the relationship between the morphology of the active layer and the photoelectric process of devices, it is obvious that the active layer should possess a highly crystalline interpenetrating network with a proper domain size and face-on molecular orientation.

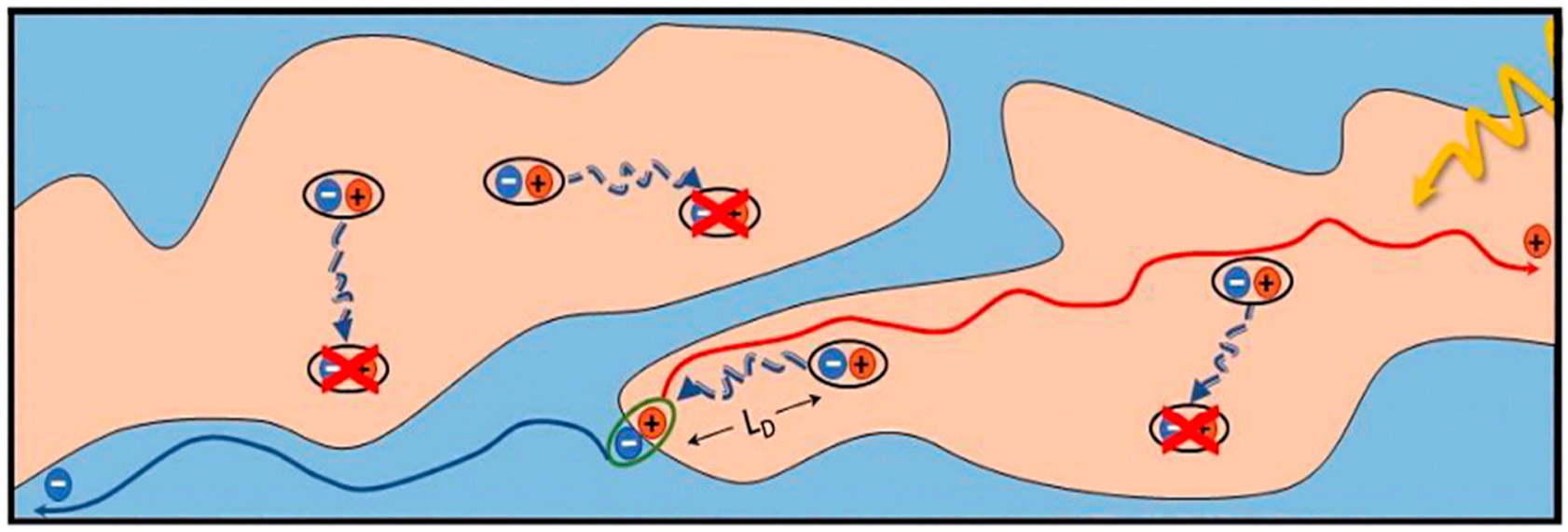

Figure 1. Schematic illustration of exciton dissociation and carrier transport in large phase domains. Reproduced from [43]. Reprinted with permission from ref. [43]. Copyright 2018 MDPI.

Therefore, on the basis of molecular tailoring [44,45], researchers have invented a variety of methods for optimizing the morphology of the active layer. One of most widely used effective methods is thermal annealing (TA), which can enhance the molecular stack and degree of crystallinity of the donor and acceptor [46-50]. For example, in P3HT:SF-HRblend thin films, the diffraction intensity becomes much clearer, which means the degree of crystallinity of both the donor and acceptor increases dramatically after TA at $120^{\circ} \mathrm{C}$ [51]. Similar to TA, solvent vapor annealing (SVA) is also an effective method to optimize the film morphology [52-56]. Hou et al. used a dichloromethane SVA-treated DRTB-T:ICC6IDT-IC-based blend film for $60 \mathrm{~s}$, and the ordered aggregation of donor and acceptor was promoted, which facilitated the formation of an interpenetrating network structure. This optimized phase separation structure is conducive to the exciton dissociation and carrier transport, boosting the PCE of the device from 5.03\% to 9.08\% [57]. However, it is a challenge to combine the two methods for practical large area manufacture, for TA is difficult to employ to treat flexible substrates of low glass transition temperature, and SVA is not compatible with the roll-to-roll process [58,59]. A number of research teams have recently made advances without using either method [60-63].

Furthermore, the morphology of the BHJ active layer closely depends on the filmforming process of solution processing [64-68]. During the evaporation of the solvent, the solution layer gradually evolves from the liquid state to solid state on the substrate, and 
the formed film is frozen in a thermodynamic metastable state. The film-forming process decides the film quenching depth of the frozen state. For example, through extending the film-forming time, the donor and acceptor molecules have sufficient time to diffuse and rearrange, leading to enhanced crystallinity of the film and increased domain sizes. If the donor and acceptor are precipitated simultaneously in a short time during the filmforming process, the degree of crystallinity of both the donor and acceptor is low due to the insufficient self-aggregating time. Therefore, controlling the kinetics of film-forming process can also regulate the morphology of the active layer.

This review focuses on the influence of the film-forming kinetics process on the morphology of the active layer in OSCs, and the underlying mechanisms are revealed. Furthermore, methods used to regulate the film-forming kinetics process are summarized and representative examples are given and discussed to understand the key parameters of tuning the film-forming process. Finally, a future control and development of film-forming kinetics is briefly outlined, which may give some guidance to achieve a high PCE of OSCs. Here, we summarize in Table 1 the critical works on film-forming kinetics in OSCs, and the cartoon illustration is shown in Figure 2.

Table 1. Summary of the performance of the OSC's active layer previously reported (some full names corresponding to the abbreviations are listed below).

\begin{tabular}{|c|c|c|c|c|c|c|}
\hline Active Layer & Conditions & $V_{\text {OC }}[\mathrm{V}]$ & $J_{\mathrm{SC}}\left[\mathrm{mA} \mathrm{cm}{ }^{-2}\right]$ & FF [\%] & $\mathrm{PCE}_{\max }[\%]$ & Ref. \\
\hline \multirow{3}{*}{ P3НT:РCBM } & Solvent CB & 0.64 & 1.63 & 52.3 & 0.58 & \multirow{3}{*}{ [69] } \\
\hline & Additive ODT $0.5 \%$ & 0.55 & 8.23 & 68.8 & 3.13 & \\
\hline & Additive $\mathrm{CN} 4 \%$ & 0.55 & 7.87 & 68.2 & 3.01 & \\
\hline \multirow{2}{*}{ PTzBI-Si:N2200 } & Solvent CB & 0.87 & 4.58 & 51.14 & 2.04 & \multirow{2}{*}[70]{} \\
\hline & Solvent MTHF & 0.88 & 17.62 & 75.78 & 11.76 & \\
\hline \multirow{2}{*}{ PBDB-T:INPIC-4F } & Cast under strong SV & 0.84 & 12.8 & 60.5 & 6.5 & \multirow{2}{*}{ [71] } \\
\hline & Cast on $100^{\circ} \mathrm{C}$ HS & 0.82 & 21.8 & 73.2 & 13.1 & \\
\hline \multirow{3}{*}{ PTB7-th:P(NDI2OD-T2) } & Solvent CN & 0.79 & 1.24 & 55 & 0.6 & \multirow{3}{*}{ [72] } \\
\hline & Solvent $o-\mathrm{DCB}$ & 0.77 & 6.82 & 51 & 2.86 & \\
\hline & Solvent CB & 0.78 & 8.86 & 50 & 3.63 & \\
\hline$P h-{ }^{-D T D P}{ }_{o}-\mathrm{OT}: P B D B-T$ & Additive $1-\mathrm{CN} 0.2 \%$ & 0.87 & 15.00 & 58.60 & 7.65 & \multirow{7}{*}{ [74] } \\
\hline$P h$-DTDP ${ }_{o}$-OTE:PBDB-T & Additive $1-\mathrm{CN} 0.5 \%$ & 0.88 & 18.28 & 68.57 & 10.98 & \\
\hline$P h-\mathrm{DTDP}_{o}-\mathrm{TE}: \mathrm{PBDB}-\mathrm{T}$ & Additive $1-\mathrm{CN} 0.7 \%$ & 0.82 & 20.83 & 71.14 & 12.21 & \\
\hline \multirow{4}{*}{ PDFQx3T:P(NDI2OD-T2) } & Solvent CF & 0.80 & 10.58 & 60 & 5.11 & \\
\hline & Solvent CB & 0.79 & 9.12 & 61 & 4.43 & \\
\hline & Solvent DCB & 0.80 & 8.44 & 60 & 4.04 & \\
\hline & Solvent XY & 0.79 & 7.91 & 61 & 3.83 & \\
\hline \multirow{2}{*}{ FTAZ:ITIC-Th } & \multirow{2}{*}{$\begin{array}{c}\text { Solvent CF } \\
\text { Additive ODT:DIO } \\
0.375 \%: 0.125 \%\end{array}$} & 0.907 & 16.8 & 62.57 & 9.72 & \multirow{2}{*}[75]{} \\
\hline & & 0.922 & 17.78 & 66.64 & 11.15 & \\
\hline \multirow{2}{*}{ P3HT:O-IDTBR } & Solvent CB & 0.77 & 8.81 & 64 & 4.45 & \multirow{2}{*}{ [42] } \\
\hline & Additive TCB $2 \%$ & 0.76 & 13.49 & 70 & 7.18 & \\
\hline \multirow{4}{*}{ PCPDTBT/C71-PCBM } & Solvent CB & 0.66 & 11.74 & 43 & 3.35 & \multirow{4}{*}{ [76] } \\
\hline & Additive HS- $\mathrm{C}_{8} \mathrm{H}_{16}-\mathrm{SH} 2.5 \%$ & 0.64 & 14.48 & 49 & 4.50 & \\
\hline & Additive $\mathrm{Br}-\mathrm{C}_{8} \mathrm{H}_{16}-\mathrm{Br} 2.5 \%$ & 0.64 & 15.26 & 48 & 4.66 & \\
\hline & Additive $\mathrm{I}-\mathrm{C}_{8} \mathrm{H}_{16}-\mathrm{I} 2.5 \%$ & 0.61 & 15.73 & 53 & 5.12 & \\
\hline P3HT/PCBM & $\mathrm{CB} /$ tetralin 1:0.05 & - & 5.76 & 60 & 1.96 & [77] \\
\hline
\end{tabular}




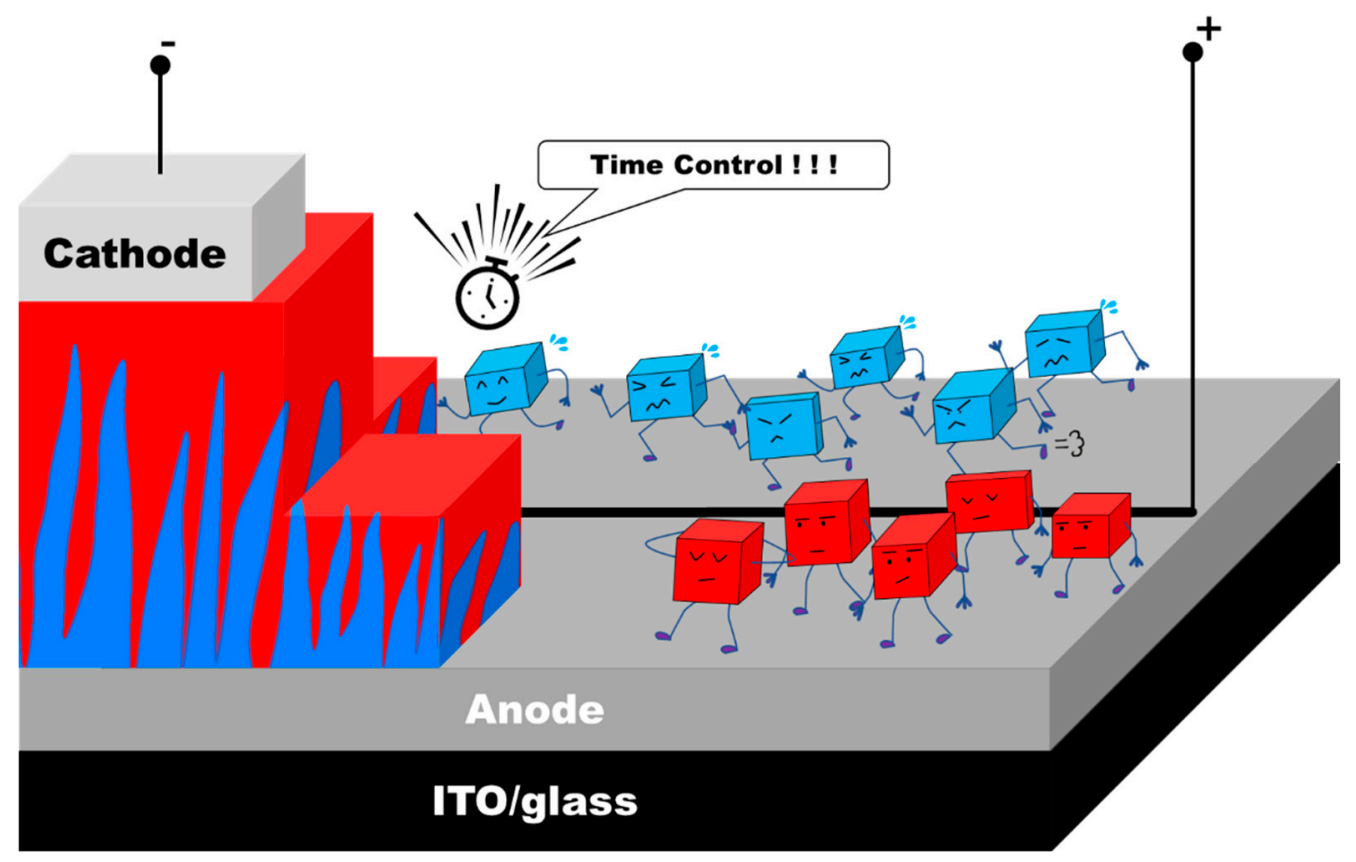

Figure 2. Cartoon illustration of film-forming dynamics.

2. The Effect of the Film-Forming Kinetics on Film Morphology

2.1. The Film-Forming Kinetics Affect the Degree of Crystallinity of the Blend Film

Due to the semicrystalline character of the conjugated molecules, the crystalline phase and amorphous phase always coexist in the active layer [78-83]. For the crystalline phase, the degree of intermolecular coupling is high, which reduces the energy barrier of carrier transport and is of benefit for carrier mobility [84]. For the amorphous phases, the large energy barrier is averse to carrier transport. However, if the duration of the film-forming process is too short, the time for molecules in the solution to diffuse and self-organize is insufficient. Consequently, most molecules tend to be frozen in the amorphous state, which leads to a low degree of crystallinity. Therefore, extending the film-forming duration is an effective strategy to improve the crystallinity.

Adding additives or using a solvent with a high boiling point (b.p.) can prolong the film-forming process effectively. Professor DeLongchamp's group investigated the effect of additives, 1,8-octanedithiol (ODT, b.p. $\approx 270{ }^{\circ} \mathrm{C}$ ) and 1-chloronaphthalene $(\mathrm{CN}$, b.p. $\approx 263{ }^{\circ} \mathrm{C}$ ), on the film-forming process of poly (3-hexylthiophene) (P3HT)/phenylC61-butyric acid methyl ester (PCBM) blend solution, and the main solvent was chlorobenzene $\left(\mathrm{CB}\right.$, b.p. $\left.\approx 131{ }^{\circ} \mathrm{C}\right)[69]$. From the extinction coefficient ratio and the evolution of film thickness (Figure 3c,d,f,g), it is clear that the film-forming duration was prolonged from ca. $20 \mathrm{~s}$ to $30 \mathrm{~s}$ and even $110 \mathrm{~s}$, respectively. The extended film-forming process provides enough time for the self-aggregation of both P3HT and PCBM. As a result, the relative crystal diffraction value of the film with $2 \%$ ODT or $2 \% \mathrm{CN}$ (the percentages here and below by volume to the main solvent) increased from the initial 0.6 to more than 0.8 . The improved degree of crystallinity facilitates carrier transport, and hole mobility and charge extraction can be impacted positively through additive processing $[85,86]$. Take the addition of ODT for instance: the addition of additive increased the $J_{\mathrm{SC}}$ from $1.67 \mathrm{~mA} / \mathrm{cm}^{2}$ to $8.87 \mathrm{~mA} / \mathrm{cm}^{2}$, boosting the PCE from $0.58 \%$ to $3.13 \%$. 


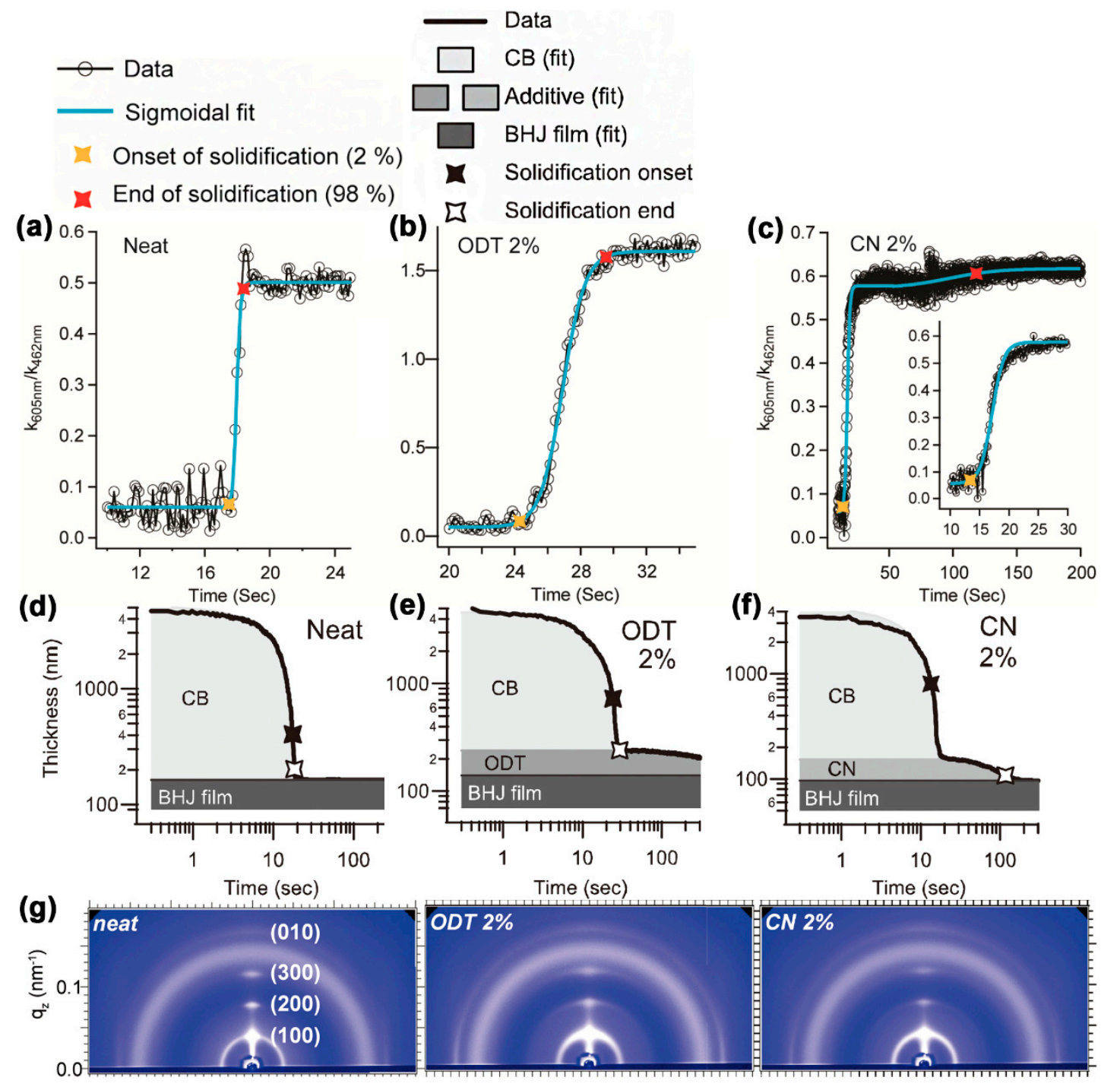

Figure 3. The film-forming process of P3HT/PCBM blend from CB solution (a,d) without additives, (b,e) with $2 \%$ ODT and $(\mathbf{c}, \mathbf{f})$ with $2 \% \mathrm{CN}$. $(\mathbf{a}-\mathbf{c})$ The evolution of the extinction coefficient $(\mathrm{k})$ at $605 \mathrm{~nm}$ to $\mathrm{k}$ at $462 \mathrm{~nm}$. (d-f) Film thickness evolution. (g) GIWAXS diffraction patterns of different solid films. Reproduced from [69]. Reprinted with permission from ref. [69]. Copyright 2013 Wiley.

Not only was the crystallinity of the P3HT:PCBM film improved after adding ODT or $\mathrm{CN}$, the crystal size was enlarged as well. An energy-filtered transport electron microscope (EFTEM) was employed to characterize the variation in crystal size. As shown in Figure $4 b-d$, the crystal size of P3HT was just a few nanometers in both the wide and long directions, while after the addition of additive, the width of the $\mathrm{P} 3 \mathrm{HT}$ fibers increased to 20 30 nm, and its length was approximately several hundred nanometers. Meanwhile, tiny nodule structures of PCBM phases also exist among P3HT nanofibers, which guarantee the exciton dissociation. This phenomenon can be explained in the view of ratio of characteristic length scale $(R)$ to exciton diffusion length $\left(R_{S}\right)$, which has a positive correlation with the crystallinity and phase purity. The group characterized the $R_{S}$ using in situ fluorescence spectroscopy (PL spectroscopy) [87]. The results show that the $R / R_{S}$ increased to $\sim 0.7$ and $\sim 0.95$ after the addition of additive due to the increased phase purity and crystallinity [88]. Consequently, the highest exciton dissociation efficiency (about 94\%) and high internal quantum efficiency (IQE) could be obtained from the device processed by adding $2 \% \mathrm{CN}[89]$. 


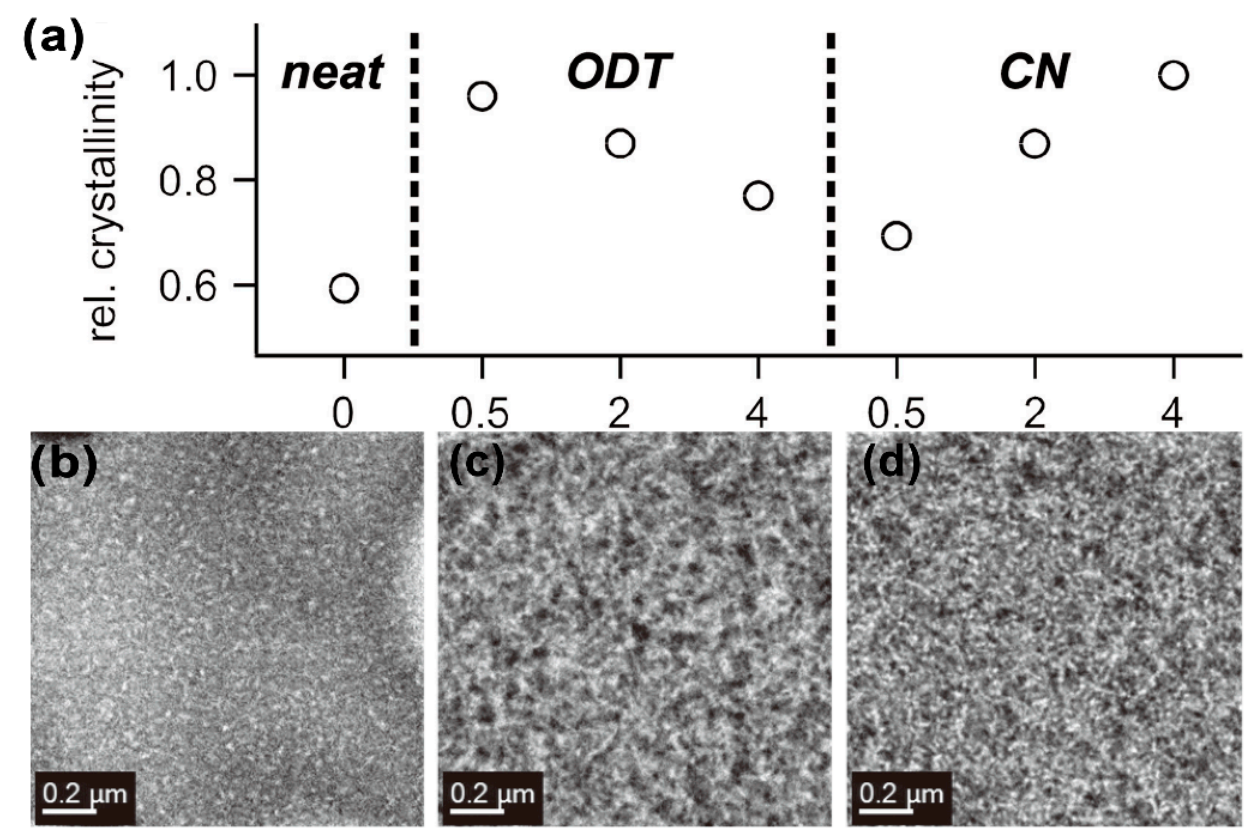

Figure 4. (a) The final relative crystallinity of P3HT/PCBM blend BHJ film from CB solution without additives and with additives in different concentrations. TEM images of films processed (b) with no additive, (c) with $2 \%$ ODT, and (d) with $2 \%$ CN. P3HT domain is bright, PCBM domain is dark. Reproduced from [69]. Reprinted with permission from ref. [69]. Copyright 2013 Wiley.

To further reveal the underlying mechanism of the formation of solid films under different solvent systems, in situ grazing incidence wide-angle X-ray scatting (GIWAXS), in situ spectroscopic ellipsometry (SE) and the film thickness test were employed to study the film-forming kinetics [90]. As shown in Figure 5, without any additives, the main solvent CB evaporates quickly and the film-forming time is very short. This fast filmforming process cannot provide sufficient time for the donor and acceptor to aggregate and crystallize, resulting in both the donor and acceptor being in a frozen amorphous state. When CN was added, after CB was fully evaporated, P3HT crystal and CN solution of the donor and acceptor remained in the film. Additionally, P3HT can aggregate at a lower degree of supersaturation in $\mathrm{CN}$ and ODT; hence, P3HT continues to crystallize during $\mathrm{CN}$ and ODT evaporation. Furthermore, the $\mathrm{CN}$ and ODT can selectively dissolve PCBM, inferred from Table 2. Additionally, after the crystallization of P3HT, the PCBM can diffuse out from the P3HT domains. Furthermore, the ODT avoids excessive crystallization of the donor, which makes the crystallinity more balanced.

Table 2. Solubility of P3HT and PCBM in CB, ODT and CN.

\begin{tabular}{cccc}
\hline \multirow{2}{*}{ Solvent } & \multicolumn{2}{c}{ Solubility $(\mathbf{m g} / \mathbf{m L})$} \\
\cline { 3 - 4 } & Chlorobenzene (CB) & P3HT & PCBM \\
\hline \multirow{2}{*}{ Additives } & 1,8 -octanedithiol (ODT) & 14 & 35 \\
\cline { 2 - 4 } & 1-chloronaphthalene (CN) & 6.50 & 30 \\
\hline \multirow{2}{*}{ 1-che } & & 37 \\
\hline
\end{tabular}




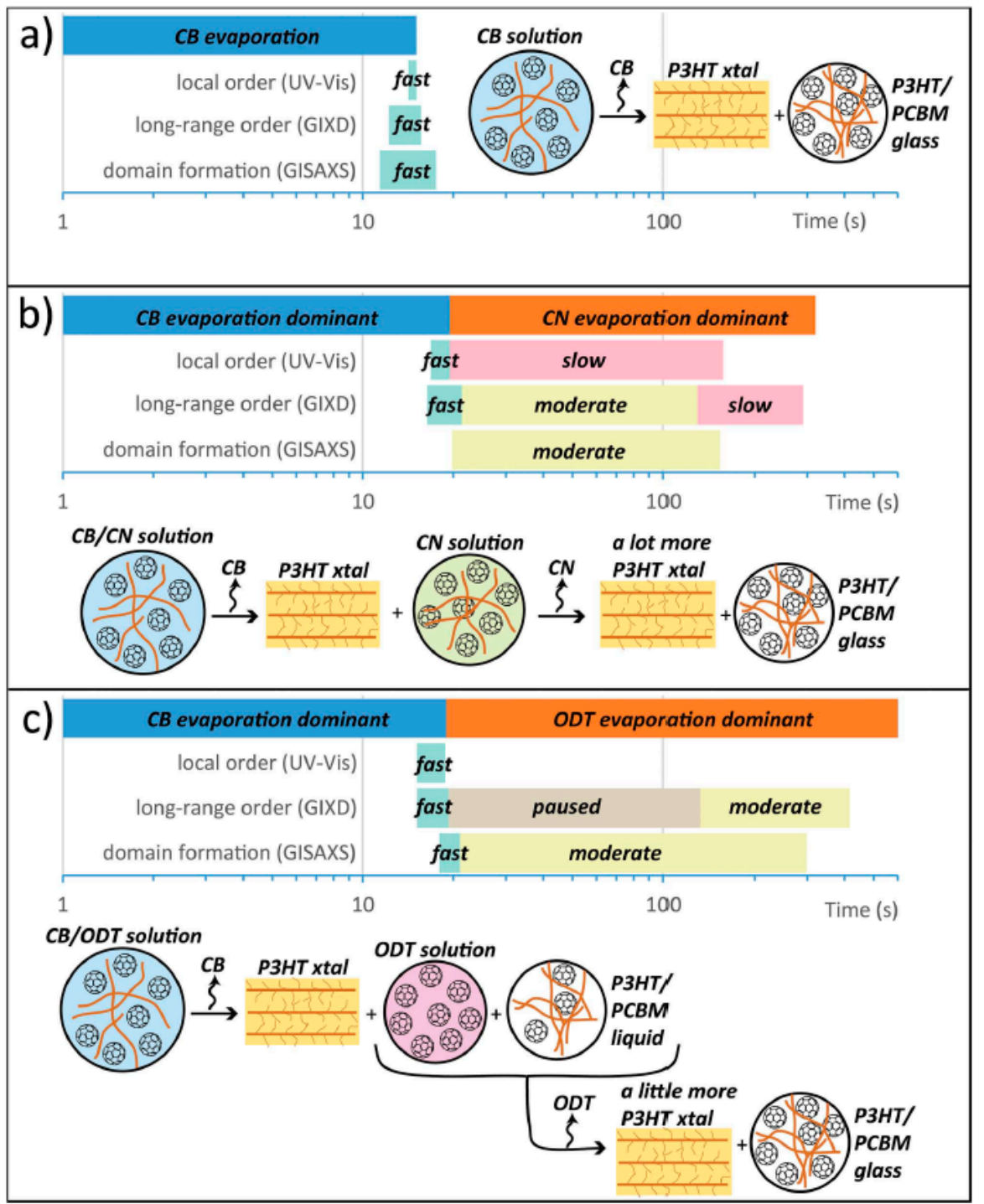

Figure 5. Schematic image of the film drying process in different solvent systems: (a) CB only, (b) CB with CN additive, and (c) CB with ODT. Reproduced from [90]. Reprinted with permission from ref. [90]. Copyright 2014 Wiley.

Besides the typical polymer/PCBM blends, extending the film-forming process could also improve the crystallinity of all-small molecular blends and all-polymer blends. McDowell C. et al. studied the different influence of $\mathrm{CB}$ /polystyrene (PS) binary solvent and $\mathrm{CB} / \mathrm{PS} / 1,8$-diiodooctane (DIO, b.p. $\approx 168^{\circ} \mathrm{C}$ ) ternary solvent on the film-forming process of the 7,7'-(4,4-bis(2-ethylhexyl)-4H-silolo [3,2-b:4,5-b']dithiophene-2,6-diyl)bis(6fluoro-4-(5'-hexyl-[2,2'-bithiophen]-5yl)-benzo[c][1,2,5]thiadiazole $\left(p-\mathrm{DTS}\left(\mathrm{FBTTh}_{2}\right)_{2}\right) /$ [6,6]-phenyl $\mathrm{C}_{71}$-butyric acid methyl ester $\left(\mathrm{PC}_{71} \mathrm{BM}\right)$ blends [91]. The film-forming duration increased from $46 \mathrm{~s}$ to $>1800 \mathrm{~s}$ after the addition of DIO (Figure 6a). In Figure $6 \mathrm{~b}$, the diffraction peaks at $4.4 \mathrm{~nm}^{-1}$ (yellow region) originated from the metastable state, and the one centered at $2.8 \mathrm{~nm}^{-1}$ (green region) corresponded to $p-\mathrm{DTS}\left(\mathrm{FBTTh}_{2}\right)_{2}$ alkyl chain stacking in crystals. The metastable GIWAXS diffraction peaks at $4.4 \mathrm{~nm}^{-1}$ disappeared, while the diffraction peaks of $p$-DTS(FBTTh $)_{2}$ alkyl chain around $2.8 \mathrm{~nm}^{-1}$ were significantly enhanced. The results indicate an enhanced degree of crystallinity, which was mainly attributed to the sufficient time for migration and rearrangement during the prolonged film-forming process, rather than freezing at a metastable state in the short film-forming process. The enhanced crystallinity of $p$-DTS( $\left(\mathrm{FBTTh}_{2}\right)_{2}$ was also confirmed in this article, as shown in Figure 6d. Compared with the morphology of film processed with CB/PS in 
Figure $6 c$, many crystalline fibrils of $p$-DTS(FBTTh $)_{2}$ can be observed interspersing the PS phases in the film processed with CB/PS/DIO (Figure 6d), which implies that more $p$-DTS(FBTTh $\left.{ }_{2}\right)_{2}$ self-organize into crystals in the extended film-forming process.
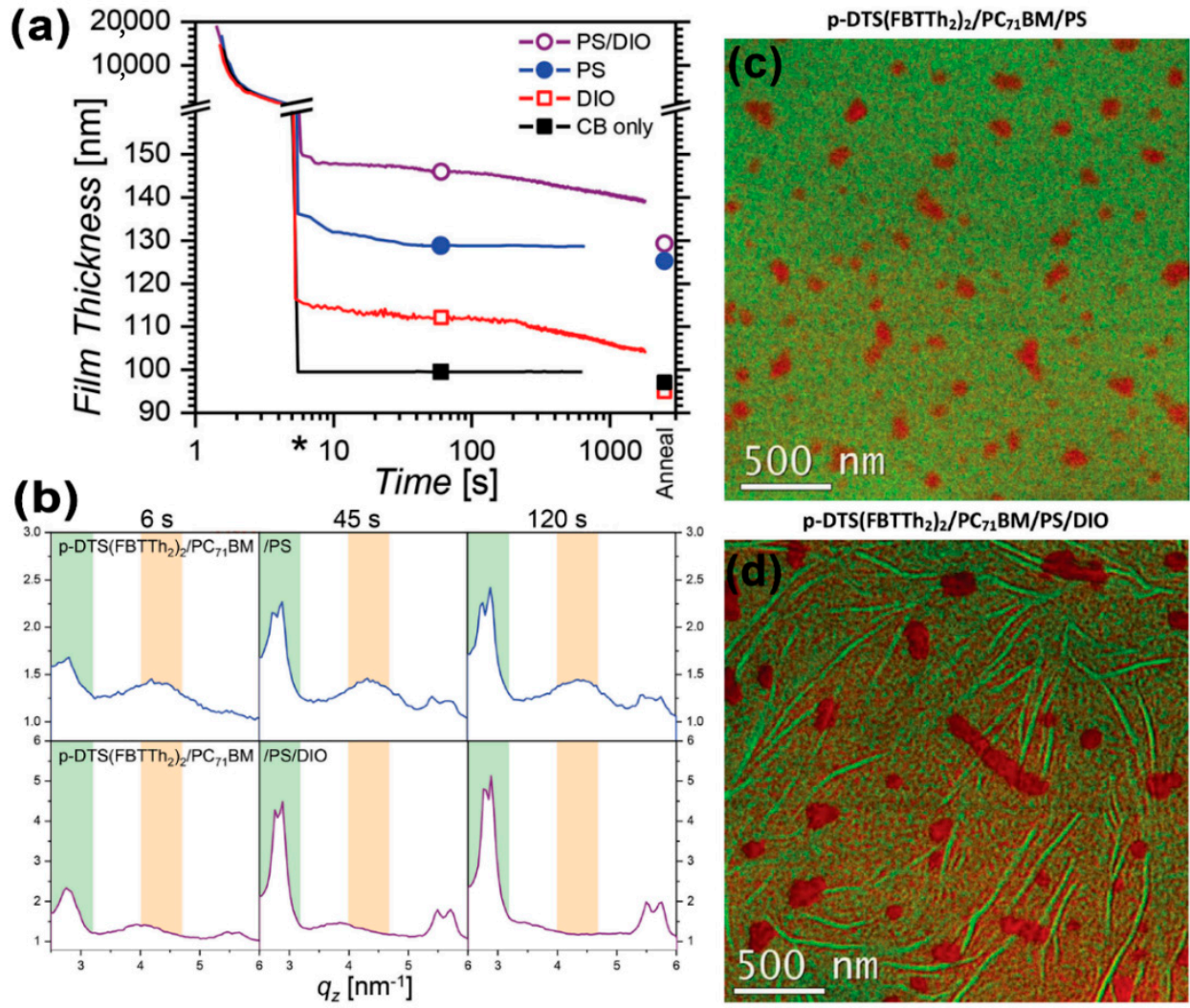

Figure 6. (a) The thickness evolution of $p$-DTS(FBTTh $)_{2} / \mathrm{PC}_{71} \mathrm{BM}$ blend film in main solvent CB without additive (black), with PS additive (blue), with DIO additive (red) and with PS and DIO additive (purple). The thinning transition is noted by *. (b) The GIWAXS diffraction intensity of $p$-DTS(FBTTh $)_{2} / \mathrm{PC}_{71} \mathrm{BM} / \mathrm{PS} / \mathrm{CB}$ and $p-\mathrm{DTS}\left(\mathrm{FBTTh}_{2}\right)_{2} / \mathrm{PC}_{71} \mathrm{BM} / \mathrm{PS} / \mathrm{DIO} / \mathrm{CB}$ blends at $6 \mathrm{~s}, 45 \mathrm{~s}$ and $120 \mathrm{~s}$ during the film-forming process. (c) EFTEM image of the dry film from $p-$ DTS(FBTTh $)_{2} / \mathrm{PC}_{71} \mathrm{BM} / \mathrm{PS} / \mathrm{CB}$ solution and (d) $p$-DTS $\left(\mathrm{FBTTh}_{2}\right)_{2} / \mathrm{PC}_{71} \mathrm{BM} / \mathrm{PS} / \mathrm{DIO} / \mathrm{CB}$ solution, green regions and red regions are $p$-DTS(FBTTh $)_{2}$-rich phases and $\mathrm{PC}_{71} \mathrm{BM}$ - and PS-rich phases, respectively. Reproduced from [91]. Reprinted with permission from ref. [91]. Copyright 2015 Wiley.

In some highly crystalline blend systems, crystallization induces phase separation, leading to a too-large domain size [92-95]. Shortening the film-forming process is an efficient way to decrease the domain size, because it could freeze more molecules in an amorphous state, which reduces the driving force of phase separation. Employing the solvent with low b.p. as the main solvent is an effective method to shorten the film-forming duration. Zhu et al. used 2-methyltetrahydrofuran (MTHF, b.p. = $80{ }^{\circ} \mathrm{C}$ ) to replace $\mathrm{CB}$ (b.p. $=132{ }^{\circ} \mathrm{C}$ ) to accelerate the solvent evaporation process of

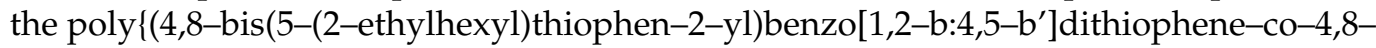
di(thien2-yl)-2-(6-(1,1,1,3,5,5,5-heptamethyltrisiloxan-3-yl)hexyl)-6octyl[1-3]triazolo[4,5f]isoindole-5,7(2H,6H)-dione $\}$ (PTzBI-Si)/poly $\{[\mathrm{N}, \mathrm{N}-9-$-bis (2-octyldodecyl)-naphthalene1,4,5,8-bis(dicarboximide)-2,6-diyl]-alt-5,50-(2,20-bithiophene)\} (N2200) blends, and the film-forming time was shortened from $11.7 \mathrm{~s}$ in CB to $\sim 3.7 \mathrm{~s}$ in MTHF (See Figure 7b) [70]. The shortened film-forming duration caused the decreased crystallinity, which suppressed the formation of large-scale phases. Meanwhile, it also reduced the diameter of fibrous PTzBI-Si crystals from larger than $400 \mathrm{~nm}$ to $35 \mathrm{~nm}$ (Figure 7a). The optimized morphology facilitated the exciton dissociation, boosting the $J_{\mathrm{SC}}$ from $2.76 \mathrm{~mA} \mathrm{~cm}^{-2}$ to $15.41 \mathrm{~mA} \mathrm{~cm}^{-2}$, which leads to the PCE being increased from $1.01 \%$ to $9.01 \%$. 


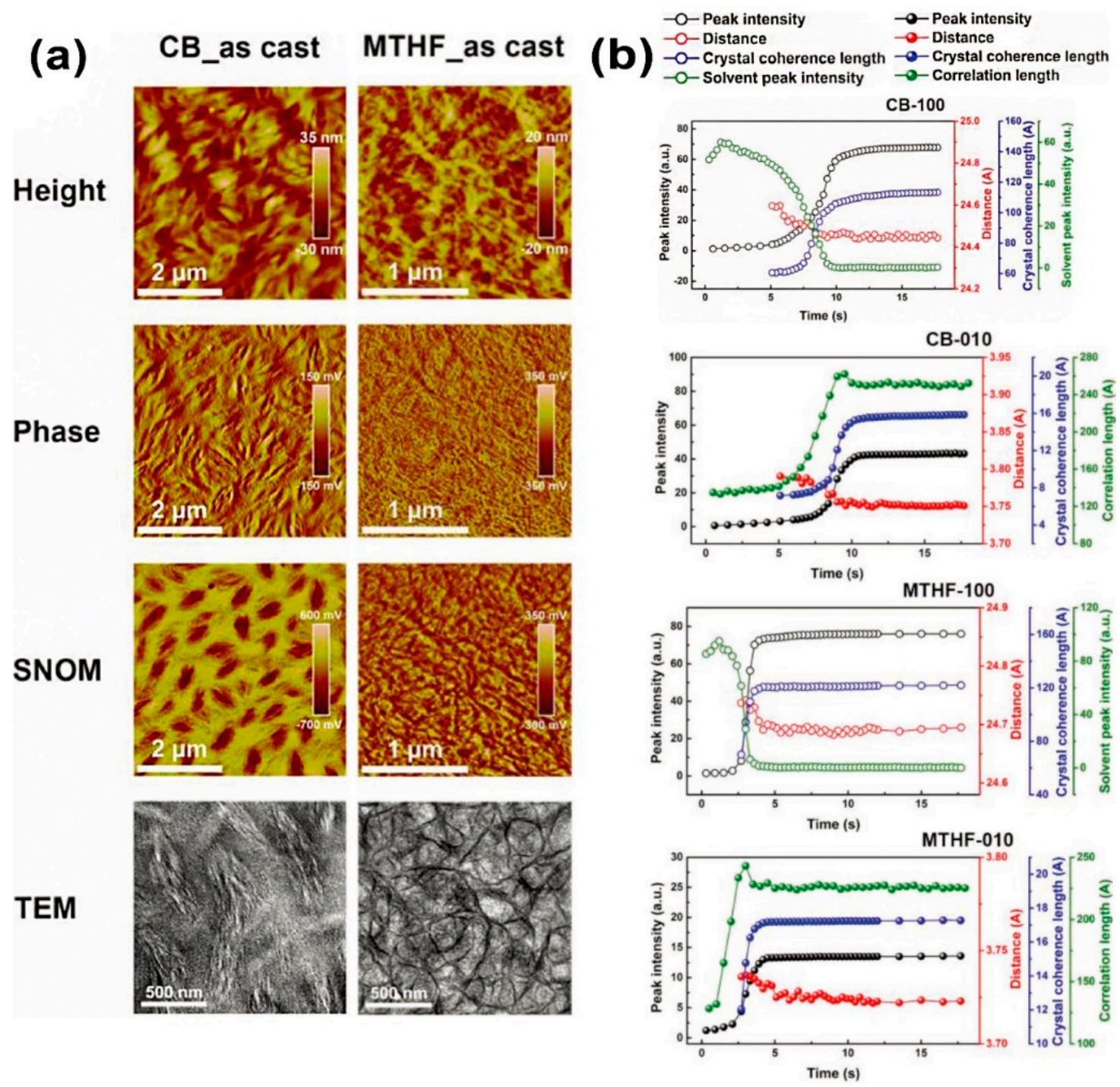

Figure 7. (a) Morphology of films treated with different solvents. Top to bottom are AFM height maps, phase diagrams, scattering-type scanning near-field optical microscopy SNOM and TEM. (b) (100) and (010) diffraction peak intensity of GIXD versus time. Reproduced from [70]. Reprinted with permission from ref. [70]. Copyright 2019 Wiley.

In addition to solvent engineering, elevating the temperature of the substrate could also shorten the film-forming process. Wang et al. shortened the film-forming process of PBDB-T/INPIC-4F (the molecular structure and energy level are shown in Figure 8a,b) blends to reduce the domain size through elevating the substrate temperature from room temperature (RT) to $100{ }^{\circ} \mathrm{C}$ [71]. INPIC-4F preferred to grow into large polycrystalline spherulites when cast on the substrate under room temperature with a solvent-vapor (SV) atmosphere due to long self-organizing time, leading to a low PCE value of $9.9 \%$ $\left(\mathrm{FF}=69.4 \%, J_{\mathrm{SC}}=17.4 \mathrm{~mA} / \mathrm{cm}^{2}\right)$. While the film was cast on the hot substrate (HS) of $100{ }^{\circ} \mathrm{C}$ without an SV atmosphere, the evaporation process of the solvent was shortened [96,97]. As a result, the large-scale crystals of INPIC-4F were inhibited, thus the value of root mean square (RMS) surface roughness was reduced from $20 \mathrm{~nm}$ to $2.8 \mathrm{~nm}$, as shown in Figure $8 \mathrm{c}-\mathrm{h}$. The optimized morphology is beneficial to exciton dissociation (increased from $94.7 \%$ to $97.4 \%$ ) and charge carrier collection (increased from $80.1 \%$ to $84.8 \%$ ). Moreover, the $\pi-\pi$ stacking of INPIC $-4 \mathrm{~F}$ was also enhanced. As shown in Figure $8 \mathrm{i}$, the diffraction peak at $1.85 \AA^{-1}$ represents the $\pi-\pi$ stacking of INPIC $-4 \mathrm{~F}$ molecules. When cast on a HS at $100{ }^{\circ} \mathrm{C}$, the position of the diffraction peak at $1.85 \AA^{-1}$ moved to a higher $\mathrm{q}_{\mathrm{z}}$. Furthermore, the absorption intensity of INPIC -4 F increased as well (Figure 8j). All of 
these imply the tighter stacking and enhanced $\pi-\pi$ packing of INPIC $-4 \mathrm{~F}$, which is of benefit for charge carrier transport. As a result, the electron and hole mobility increased from $8.7 \times 10^{-5} \mathrm{~cm}^{2} \mathrm{~V}^{-1} \mathrm{~s}^{-1}$ and $4.8 \times 10^{-4} \mathrm{~cm}^{2} \mathrm{~V}^{-1} \mathrm{~s}^{-1}$ to $6.6 \times 10^{-4} \mathrm{~cm}^{2} \mathrm{~V}^{-1} \mathrm{~s}^{-1}$ and $6.1 \times 10^{-4} \mathrm{~cm}^{2} \mathrm{~V}^{-1} \mathrm{~s}^{-1}$, respectively. Consequently, the FF increased to $73.2 \%$ and $J_{\mathrm{SC}}$ increased to $21.8 \mathrm{~mA} / \mathrm{cm}^{2}$, which boosted the PCE to $13.1 \%$.

(a)
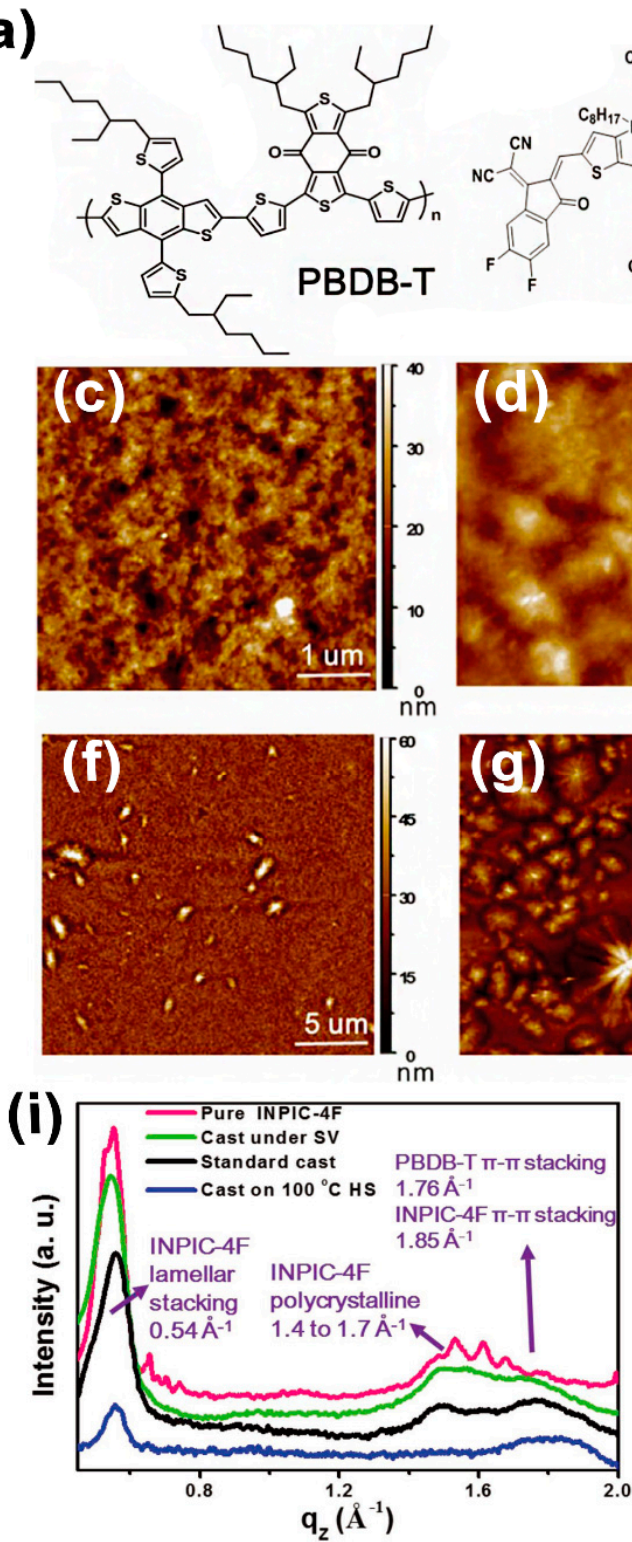

(b)

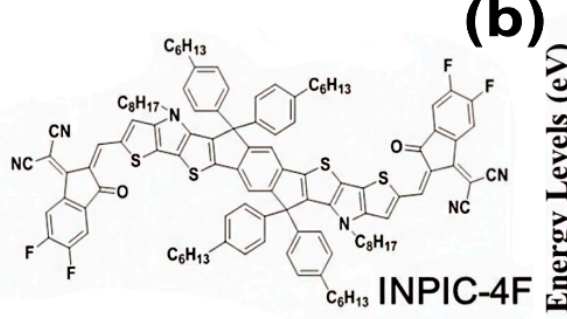

$-3.41$
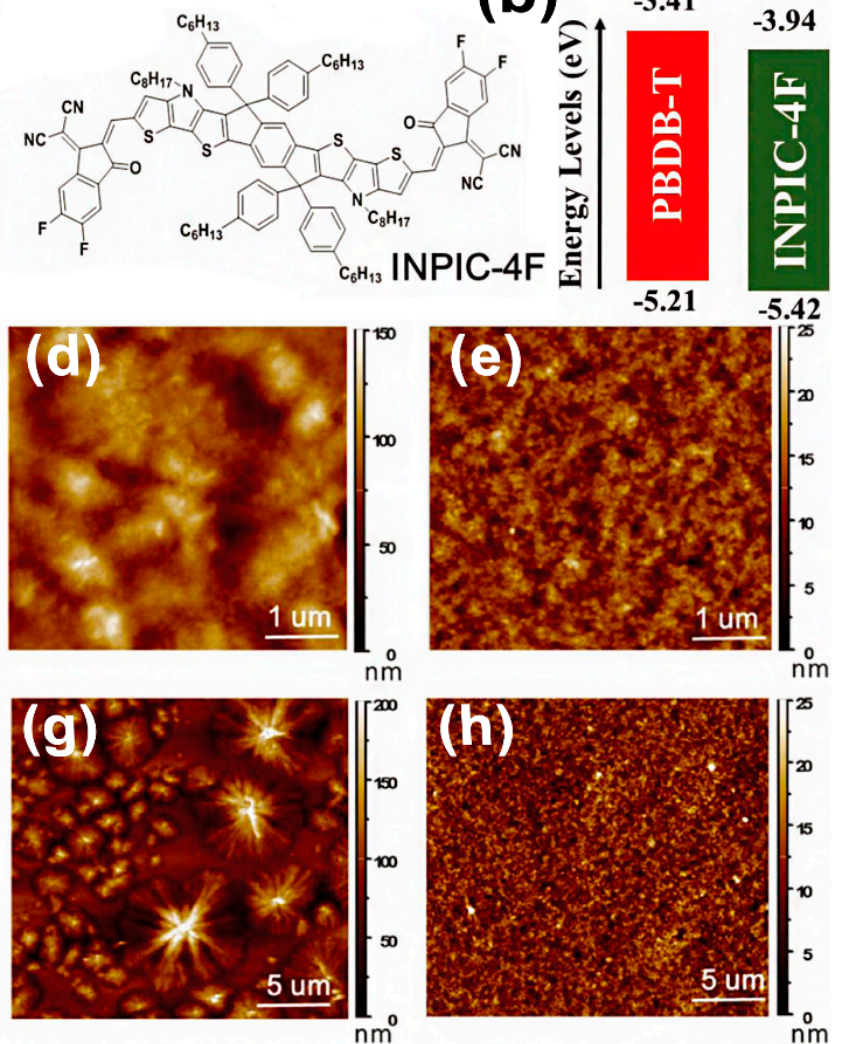

(j)

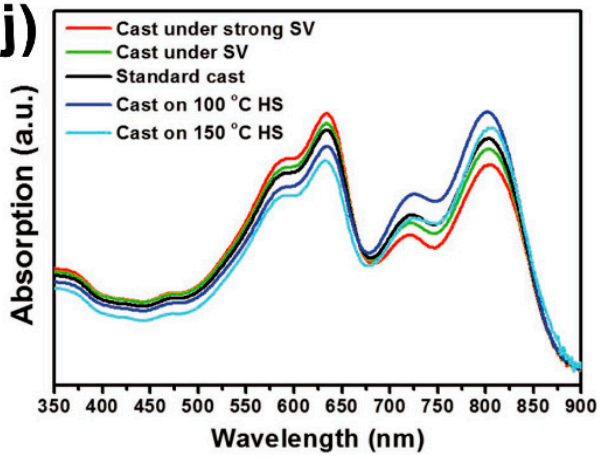

Figure 8. (a) Molecular structure and (b) energy level diagram of PBDB-T and INPIC-4F. (c-h) AFM images of PBDB-T/INPIC-4F film surfaces at different magnifications: $(\mathbf{c}, \mathbf{f})$ spin coating, $(\mathbf{d}, \mathbf{g})$ spin coating in an evaporation atmosphere, $(\mathbf{e}, \mathbf{h})$ spin coating on a thermal substrate under $100{ }^{\circ} \mathrm{C}$. (i) GIWAXS diffraction intensity image of pure INPIC-4F film, PBDB-T/INPIC-4F film cast at room temperature in an SV atmosphere, in standard case, and on HS with $100{ }^{\circ} \mathrm{C}$. (j) Absorption spectra of PBDB-T/INPIC-4F films prepared under different conditions. Reproduced from [71]. Reprinted with permission from ref. [71]. Copyright 2018 Wiley.

Thanks to the third component, the ternary blend film had a higher deformability. When the active layer contains only two components, such as PBDB-T:N2200 and PCE10:N2200 [98], either the crystallinity of the polymer is too high, resulting in a poor flexibility of the film, or the donor and acceptor have high miscibility, and it is not 
easy for them to crystallize and form a bi-continuous path conducive to charge transfer (Figure 9a). When a ternary blend film was applied (PBDB-T:PCE10:N2200, 1.2:0.8:1 by weight), the flexibility of the film was greatly improved. As shown in Figure 9b, the peaks of the binary system changed significantly before and after stretching. It reveals the film had unstable morphology under deformation. However, it is difficult to distinguish a new crystallized peak in PBDB-T:PCE10:N2200 blend film, and it was the same after thermal annealing(Figure 9c). Manifesting the stronger entanglements between the donor and acceptor would help to maintain the original morphology under deformation. In other words, appropriately reducing the crystallinity can improve the flexibility of the active layer.

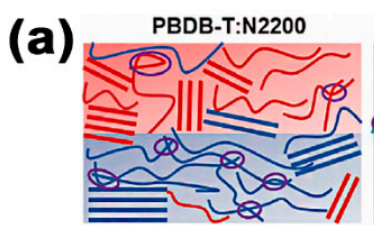

(b)

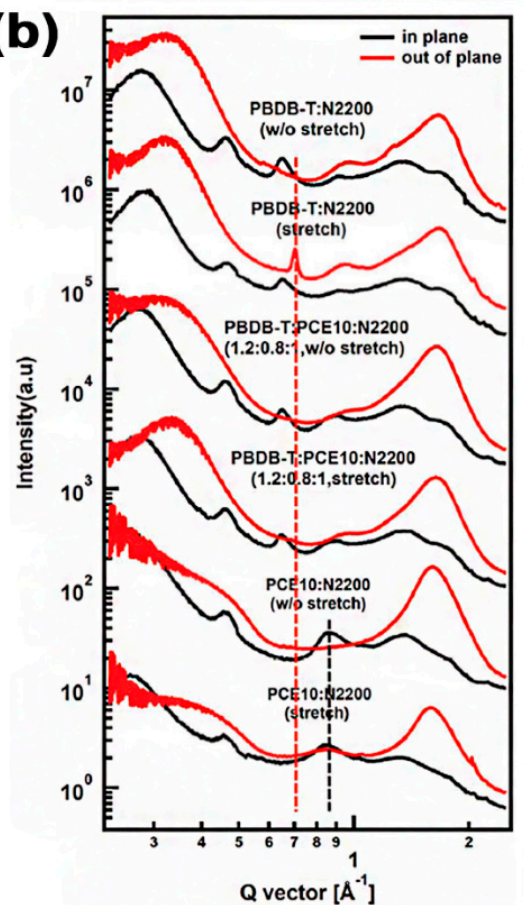

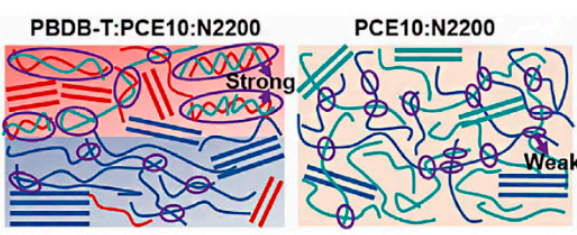

- Crystallized PBDB-T $\sim$ Amorphous PBDB-T W Amorphous N2200 - Crystallized PCE10 $W$ Amorphous PCE10

(c)

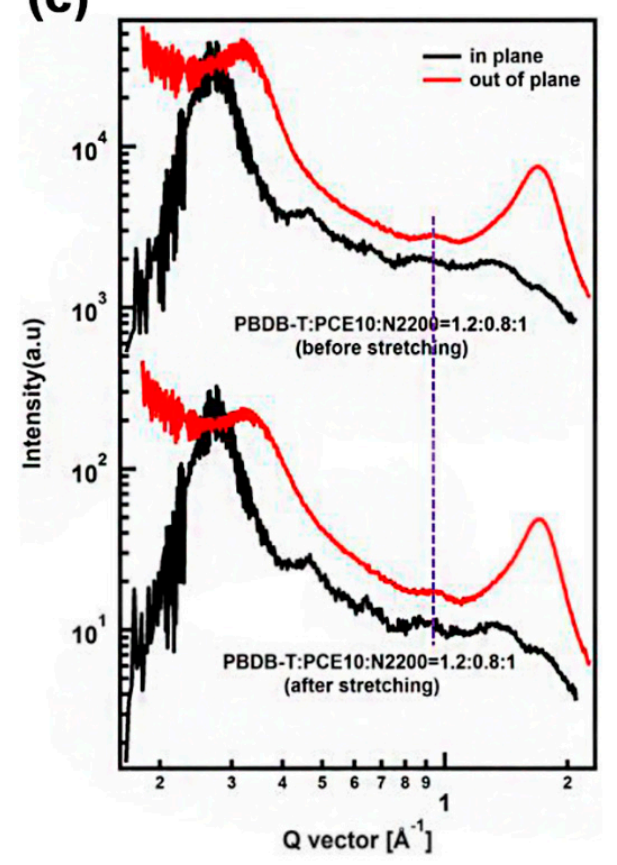

Figure 9. (a) Illustration of morphology in blend films. The part marked with a violet circle represents the intermolecular entanglement. (b) One-dimensional GIWAXS line profiles of different films before and after stretching. (c) One-dimensional GIWAXS profiles of ternary film thermally annealed under $150{ }^{\circ} \mathrm{C}$ for $20 \mathrm{~min}$ before and after stretching. Reproduced from [98]. Reprinted with permission from ref. [98]. Copyright 2021 Wiley.

Son et al. reported that the PBDB-TSCl:IT-4F blend system achieved a high PCE of $21.53 \%$ under $500 \mathrm{~lx}$ fluorescent light (FL) [99]. Figure 10a and b show that PBDB-TSCl blend film exhibits large dark regions of hundreds of nanometers across. In contrast, PBDB-TF has dark regions only tens of nanometers across, and that are relatively well intermixed among gray and white features, suggesting better intermixing between PBDBTF and acceptor. Significantly, a new peak at $\mathrm{q}_{\mathrm{xy}} 0.318 \AA^{-1}$ of the PBDB-TSCl blended film represents the intermolecular spacing of IT- $4 \mathrm{~F}$ (Figure 10c). This blended system improved not only the packing feature of the donor itself but also the crystallinity of the acceptor. The simultaneously heightened crystalline properties of the donor and acceptor cause larger phase separation in PBDB-TSCl blended film, while more miscible morphology has been observed in PBDB-TF BHJ film. Moreover, the optimized PBDB-TSCl:IT-4F film under 
indoor light and sunlight is also very different. Only $13.13 \%$ of PCE can be achieved when the film is under a 1 sun condition. The team of Hou [100] reported that the PBDB-TF:ITCC system achieved a lower PCE of $10.3 \%$ under AM $1.5 \mathrm{G}$ illumination, and a PCE of $22 \%$ under LED $2700 \mathrm{~K}$. The results reveal that OSCs can possess better performance under indoor light, and many important studies have drawn the same conclusion [101-103].

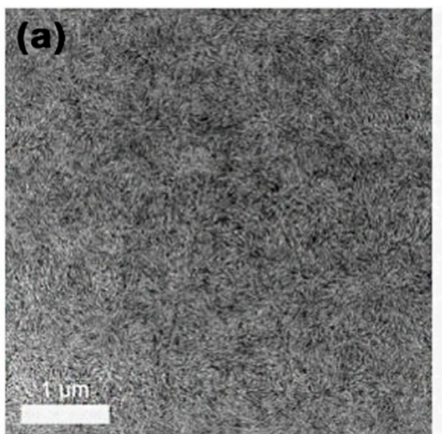

(c)

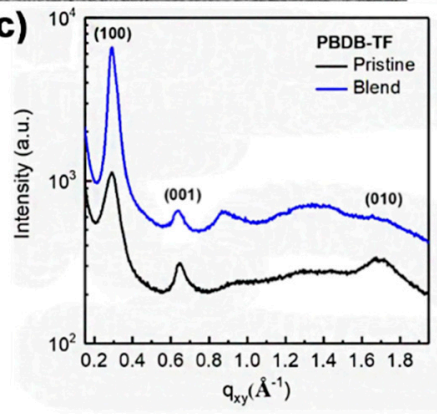

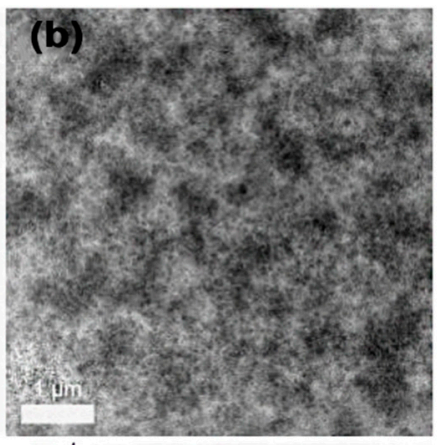

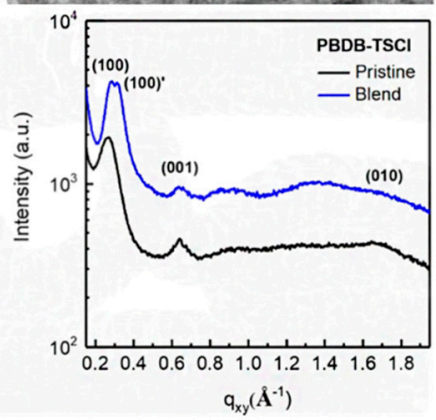

Figure 10. TEM images of (a) PBDB-TF and (b) PBDB-TSCl blend film. (c) The corresponding inplane line-cut profiles. Reproduced from [99]. Reprinted with permission from ref. [99]. Copyright 2019 American Chemical Society.

\subsection{The Film-Forming Kinetics Affect the Molecular Orientation of the Donor and Acceptor}

Conjugated molecules are highly anisotropic [104-106], and the strong electronic coupling is only expected for molecules oriented with their $\pi$ systems parallel to each other, which directly leads to the corresponding anisotropy of carrier mobility. Take P3HT for instance: the carrier mobility along the $\pi-\pi$ stacking direction is approximately $10^{-2} \mathrm{~cm}^{2} \mathrm{~V}^{-1} \mathrm{~s}^{-1}$, but the one along the alkyl side chain is lower, at only $10^{-4} \mathrm{~cm}^{2} \mathrm{~V}^{-1} \mathrm{~s}^{-1}$. It is well known that a conjugated molecule shows three different orientations in the film, i.e., edge-on (alkyl side chains are perpendicular to the substrate), face-on ( $\pi$ planes are parallel to the substrate) and flat-on orientation (the rigid backbones are perpendicular to the substrate) (Figure 11) [96]. According to the anisotropic carrier mobility, it can be deduced that the carrier transport along the direction perpendicular to the substrate is the lowest when the molecules adopt edge-on orientation. Unfortunately, the conjugated molecule tends to adopt edge-on orientation because it is its thermodynamically stable state. 


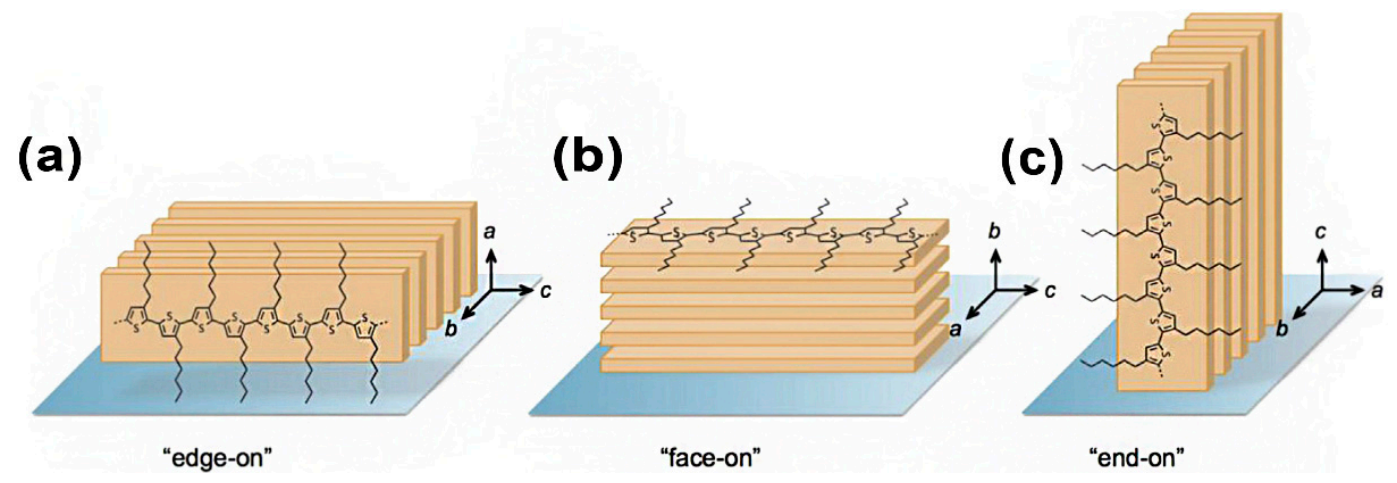

Figure 11. Three crystallographic orientations of polymer molecules. Reproduced from [96]. Reprinted with permission from ref. [96]. Copyright 2015 Elsevier.

As we mentioned above, the longer the film-forming process is, the easier is the formation of the thermodynamic stable state. Hence, the edge-on orientation would be suppressed through shortening the film-forming duration [97]. Ryu et al. [107] studied the relationship between molecular orientation and film-forming methods. The results show that when the film was castthrough drop casting, P3HT in film adopts an edge-on orientation due to the long film-forming duration (about $30 \mathrm{~min}$ ), while the film-forming duration decreased to less than 20 secs when using spin-coating. As a result, P3HT was frozen in the sub-stable face-on orientation due to the insufficient organized time. Similarly, regulating the spin speed could also modify the molecular orientation. DeLongchamp et al. [108] pointed out that P3HT film cast with faster spin speed $(2000 \mathrm{rpm})$ prefers a faceon orientation compared to the one cast with a slower spin speed $(250 \mathrm{rpm})$. Consequently, the carrier mobility measured through effect transistors (FET) increased from $1 \times 10^{-3} \mathrm{~cm}^{2}$ $\mathrm{V}^{-1} \mathrm{~s}^{-1}$ to $6 \times 10^{-3} \mathrm{~cm}^{2} \mathrm{~V}^{-1} \mathrm{~s}^{-1}$.

The solvent also determines the film-forming kinetics to a large extent apart from the film-forming method. Take poly $\left\{\left[\mathrm{N}, \mathrm{N}^{\prime}\right.\right.$-bis(2-octyldodecyl)-naphthalene-1,4,5,8bis(dicarboximide)-2,6-diyl]-alt-5,5'-(2,2'-bithiophene) $\}(\mathrm{P}(\mathrm{NDI} 2 \mathrm{OD}-\mathrm{T} 2)) /$ poly[4,8-bis(5-

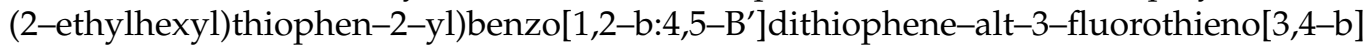
thiophene-2-carboxylate] (PTB7-th) blends for example: P(NDI2OD-T2) and PTB7-th adopted edge-on and face-on orientations, respectively, when using $\mathrm{CN}$ as a solvent [72] If $\mathrm{CN}$ was substituted by solvents with a relatively low b.p., such as $o$-dichlorobenzene $(o-\mathrm{DCB})$ and $\mathrm{CB}$, the transition of $\mathrm{P}(\mathrm{NDI} 2 \mathrm{OD}-\mathrm{T} 2)$ orientation from edge-on to face-on in the PTB7-th/P(NDI2OD-T2) blends would occur, which was illustrated in Figure 12a,b. Therefore, the electron mobility increased from $1.01 \times 10^{-5} \mathrm{~cm}^{2} \mathrm{~V}^{-1} \mathrm{~s}^{-1}$ to $6.20 \times 10^{-5} \mathrm{~cm}^{2} \mathrm{~V}^{-1} \mathrm{~s}^{-1}$ and the PCE increased from $0.53 \%$ to $3.52 \%$ (Table 3). The orientation of the $\mathrm{Ph}-\mathrm{DTDP}_{0}-\mathrm{TE}: \mathrm{PBDB}-\mathrm{T}$ blend film changed from edge-on to face-on, and the exciton dissociation probability increased from $93 \%$ to $96.3 \%$ [73]. The optimization is attributed to the consistent molecular orientation of donor and acceptor molecules, which induces a strong built-in electric field of benefit for exciton dissociation.

Table 3. Device performance of different solvent treatments.

\begin{tabular}{|c|c|c|c|}
\hline Solvent & $\mu_{h}\left(10^{-5} \mathrm{~cm}^{2} /(\mathrm{V} \mathrm{s})\right)$ & $\mu_{e}\left(10^{-5} \mathrm{~cm}^{2} /(\mathrm{V} \mathrm{s})\right)$ & PCE(\%) \\
\hline $\mathrm{CN}$ & $0.62 \pm 0.10$ & $1.01 \pm 0.16$ & $0.53 \pm 0.07$ \\
\hline$o-\mathrm{DCB}$ & $3.90 \pm 0.36$ & $2.58 \pm 0.26$ & $2.73 \pm 0.13$ \\
\hline CB & $8.40 \pm 0.69$ & $6.20 \pm 1.51$ & $3.52 \pm 0.11$ \\
\hline
\end{tabular}



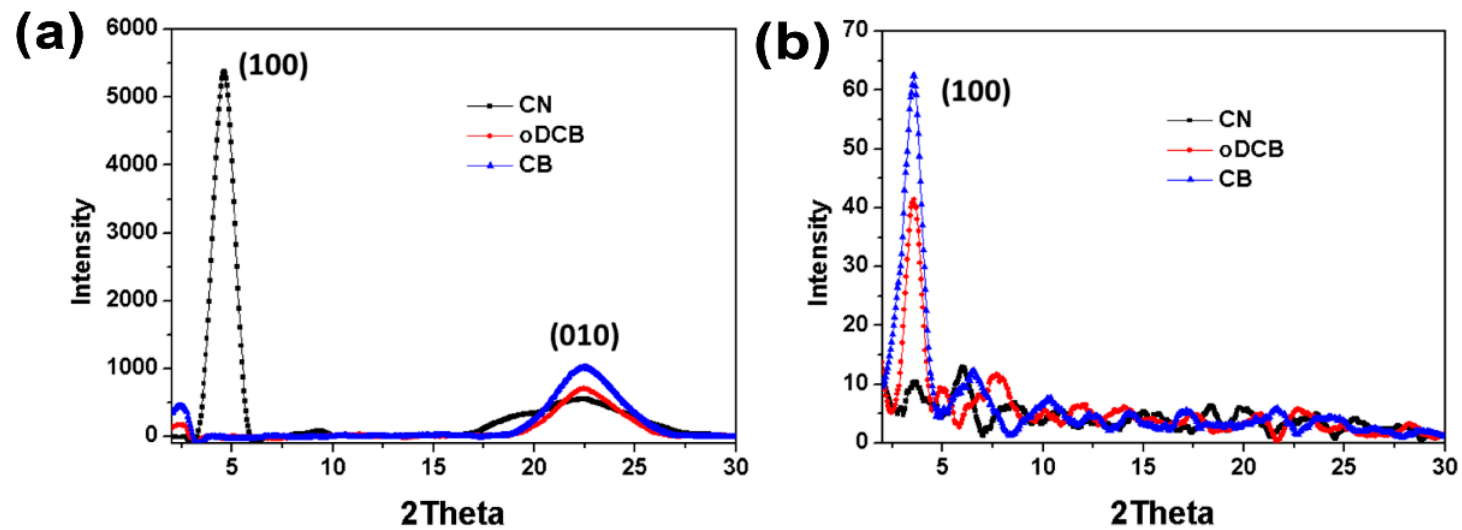

Figure 12. (a) Out-of-plane and (b) in-plane GIXD diffraction intensity for PTB7-th:P(NDI2OD-T2) = 1:1 dry BHJ film cast from CN, $o-\mathrm{DCB}$ and CB. Reproduced from [72]. Reprinted with permission from ref. [72]. Copyright 2015 American Chemical Society.

Combining the solvent engineering with the spin rate is an effective strategy to regulate the film-forming kinetics. Kitchen et al. [109] combined spin rate with solvent to regulate the orientation of $\mathrm{P} 3 \mathrm{HT}$ in $\mathrm{P} 3 \mathrm{HT} / \mathrm{PCBM}$ blends. It shows that when $o-\mathrm{DCB}$ (b.p. $180.4^{\circ} \mathrm{C}$ ) was selected as the solvent and the film was cast with a high spin rate, P3HT tended to adopt an edge-on orientation. On the contrary, choosing chloroform (CF, b.p. $61^{\circ} \mathrm{C}$ ) as the solvent and a high spin rate could promote P3HT to adopt a face-on orientation, as shown in Figure 13. It is worth noting that corresponding to the transition from edge-on to face-on, the $V_{\mathrm{OC}}$ of solar cells increased from $0.26 \mathrm{~V}$ to $0.4 \mathrm{~V}$ (as shown in Table 3). This is because the ionization energy of HOMO and the LUMO in the conjugated polymer are determined by the intrinsic surface dipoles, i.e., the HOMO level of P3HT with an edge-on orientation is higher than that with a face-on orientation. Hence, the transition in molecular orientation from edge-on to face-on of P3HT leads to an increased gap between the HOMO of P3HT and the LUMO of PCBM, thus boosting the value of $V_{\text {OC. }}$.
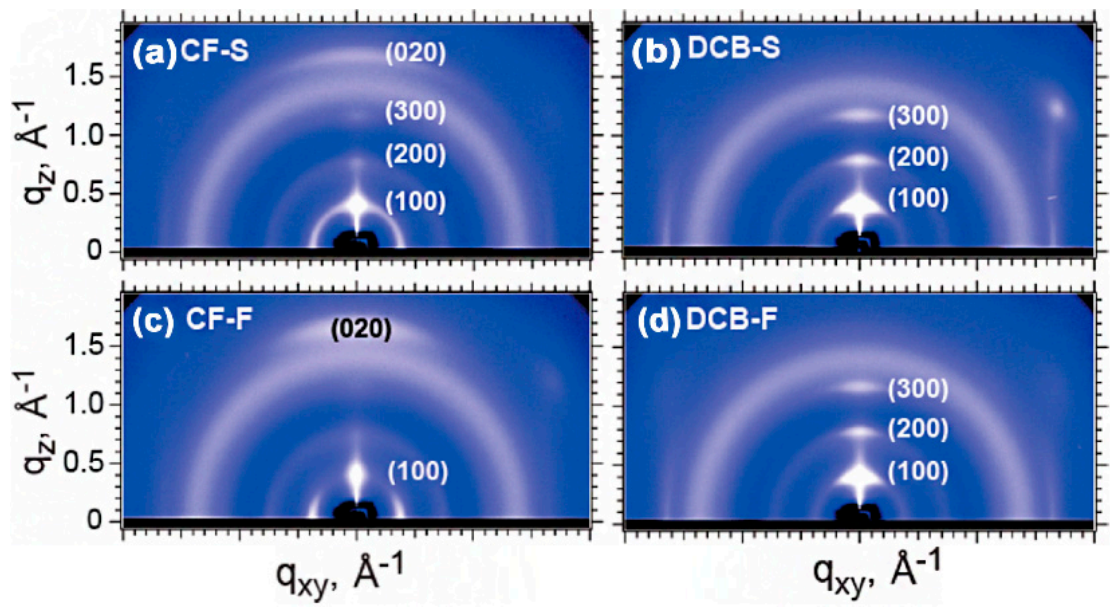

Figure 13. GIWAXS diffraction patterns of P3HT/PCBM films prepared under four different conditions. Reproduced from [109]. Reprinted with permission from ref. [109]. Copyright 2015 American Chemical Society.

\subsection{The Film-Forming Kinetics Affect the Domain Sizes of the Blend Film}

After the generation of excitons in BHJ solar cells, excitons diffuse to the interface, then separate into free carriers [110]. The diffusion length of excitons in organic semiconductor materials is usually 5 10 $\mathrm{nm}[23,24,111]$. If the domain sizes are too large, a large number of excitons cannot reach the $\mathrm{D} / \mathrm{A}$ to dissociate and recombine to the ground state, as illustrated in Figure 1. Hence, a small domain size is required for exciton dissociation. 
However, too small a phase domain would induce the recombination between electrons and holes due to Coulomb's gravity during the charge transport. Therefore, the domain size should satisfy both the requirements of exciton dissociation and charge transport, simultaneously.

During the film-forming process, the duration of coarsening usually determines domain size. Kim et al. [74] studied the relationship between the film-forming kinetics and domain size of poly\{2,5-di(2-thienyl)thiophene-alt-6,7-difluoro-2,3-bis (3,4-bis(octyloxy)phenyl)qunoxaline)\}(PDFQx3T)/P(NDI2OD-T2)) blends. They employed solvents with different b.p., including $\mathrm{CF}, \mathrm{CB}, o-\mathrm{DCB}$ and $p$-xylene $(\mathrm{XY})$, and obtained a domain size of $27 \mathrm{~nm}, 126 \mathrm{~nm}, 170 \mathrm{~nm}$ and $320 \mathrm{~nm}$, respectively. The results indicate that a solvent with low b.p. accelerates the film-forming process, which shortens the coarsening of phase separation. Compared with the large domain size $(320 \mathrm{~nm})$, the domain size of $27 \mathrm{~nm}$ is optimal for exciton quenching efficiency, which increased from $77.6 \%$ to $87.5 \%$. Consequently, $J_{\mathrm{SC}}$ increased from $7.91 \mathrm{~mA} \mathrm{~cm}^{-2}$ to $10.58 \mathrm{~mA} \mathrm{~cm}^{-2}$, thus boosting PCE from $3.83 \%$ to $5.11 \%$.

Adjusting the composition of additives is also an effective strategy for controlling the domain size. Ma et al. [75] studied the relationship between the composition of additives and domain size. In FTAZ:ITIC-Th blends, ODT could promote the nucleation of the donor and acceptor, while DIO could prolong the crystal growth process during the film-forming stage. It shows that when the ratio of ODT to DIO is 0:0.5\%, the phase domain size is $71 \mathrm{~nm}$ and the phase purity is 0.66 ; when the corresponding ratio is $0.375 \%: 0.125 \%$, the phase domain size reduces to $14 \mathrm{~nm}$ and the phase purity increases to 0.79 . They ascribed the optimized morphology and PCE to the change in the film-forming kinetics (Figure 14b,c). If only DIO exists, the film-forming duration would be extended excessively due to its high b.p. and induce a large domain size. When adding ODT as the other additive, the volatile ODT could induce the nucleation within $100 \mathrm{~s}$, while DIO still existed in the film for a longer period ( $>100 \mathrm{~s}$ ), which could further promote the crystal growth. Due to the compromise between nucleation and crystal growth, the domain size was decreased, while the domain purity was increased. The optimized morphology is of benefit for exciton dissociation and charge transport, leading to the average PCE increasing from $9.04 \%$ to $10.93 \%$.

As we mentioned above, too small a domain size is not beneficial for the charge transport, and extending the film-forming duration is an effective method to enlarge the domain size [112]. Barrena et al. [113] decreased the flow rate of the dry gas $\left(\mathrm{N}_{2}\right)$ and the film-forming temperature (Figure $14 \mathrm{~d}$ ) to extend the film-forming duration of the $\mathrm{P} 3 \mathrm{HT} / \mathrm{PCBM}$ blend. When the flow rate was decreased to $0.5 \mathrm{~m} / \mathrm{s}$, changing the filmforming temperature from $40{ }^{\circ} \mathrm{C}$ to $15^{\circ} \mathrm{C}$, the film-forming duration was prolonged, from less than $100 \mathrm{~s}$ to around $1100 \mathrm{~s}$. The prolonged duration provides enough time for phase coarsening, resulting in a larger domain size, which can be deduced by the increased large root mean square (RMS) from less than $2.5 \mathrm{~nm}$ to around $25 \mathrm{~nm}$. The enlarged domain size could suppress the biomolecular recombination, increasing $J_{\mathrm{SC}}$ from $3.2 \mathrm{~mA} / \mathrm{cm}^{2}$ to $7.2 \mathrm{~mA} / \mathrm{cm}^{2}$. Similarly, adding a high-b.p. additive could increase the domain size as well. Manley et al. [114] extended the film-forming duration of PTB7 film from about $9 \mathrm{~s}$ to $5580 \mathrm{~s}$ by adding DIO, and the coherence lengths (CLs) increased from 1.99 to $2.36 \mathrm{~nm}$, whose effect of optimizing PCE has been verified [115]. 

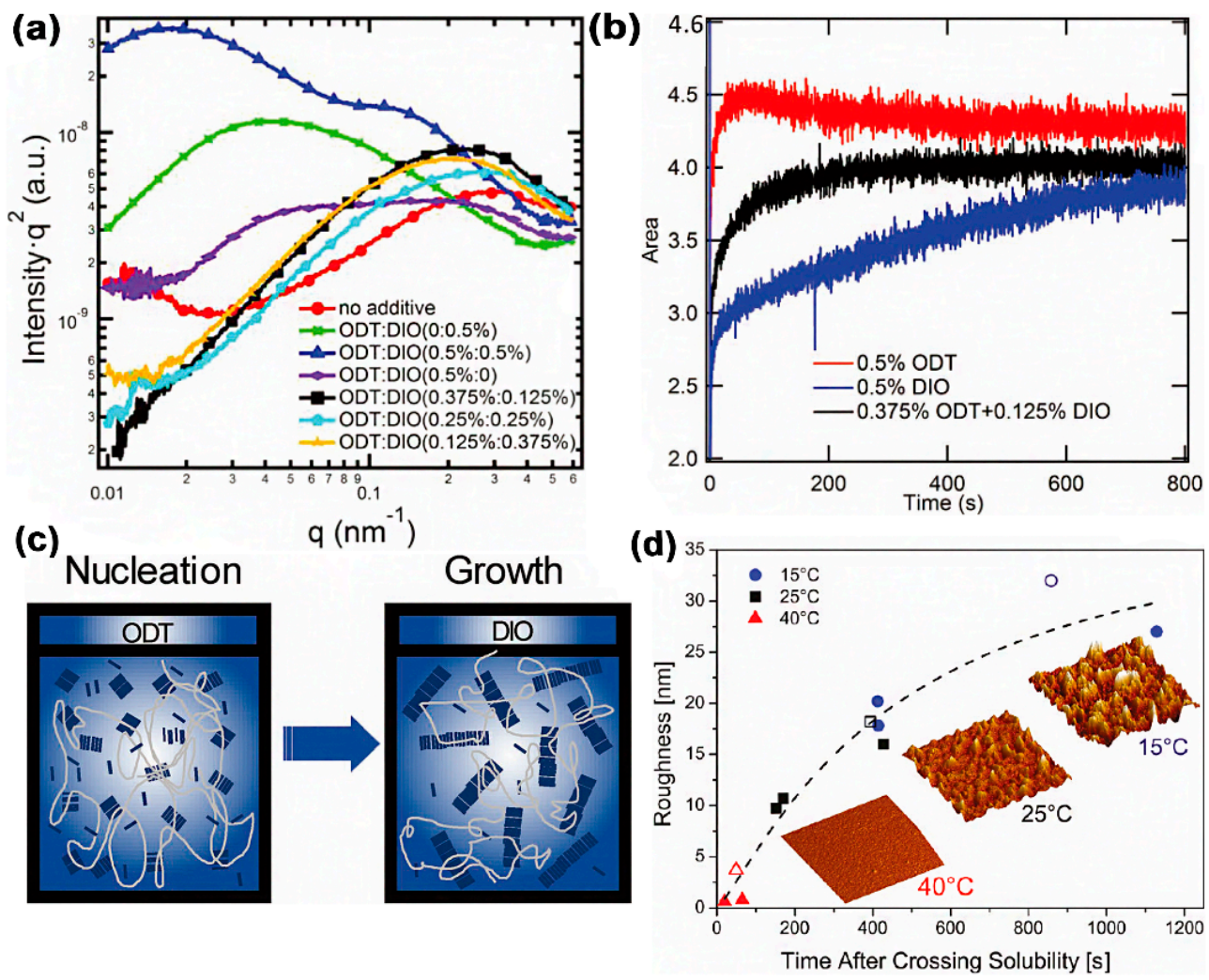

Figure 14. (a) Reduced RSoXS data of films with different composition. (b) In situ GIWAXS data of the (010) diffraction peak of FTAZ/ITIC-Th(1:1.5, w/w) films processed from additives of different composition. (c) Schematic of the effect of ODT and DIO additives on the crystallinity of the active layer. Reproduced from [75]. (d) The evolution of roughness of films deposited under various temperatures (Solid is P3HT/PCBM, hollow is pure P3HT). Reproduced from [112]. Reprinted with permission from ref. [75]. Copyright 2019 Wiley; Reprinted with permission from ref. [112]. Copyright 2011 American Chemical Society.

\subsection{The Film-Forming Kinetics Affect the Phase Separation Structure of the Blend Film}

In order to ensure effective carrier transport to the corresponding electrodes, the donor and acceptor should form continuous phases, i.e., bi-continuous lateral phase separation or an interpenetrating network [116]. If the donor and/or acceptor form an isolated islandlike phase separation structure, the bimolecular recombination of the carrier would be serious, which would cause a low FF and $J_{\mathrm{SC}}$ of the device. In addition to the lateral bicontinuous structure, the vertical phase separation structure, referring to the distribution of the donor and acceptor in the perpendicular direction to the substrate, also plays an important role in the charge transport and collection. Recent studies show that an ideal vertical phase separation structure should be described as donors enrich near the anode and acceptors enrich near the cathode, which is expected to improve the charge transport and collection efficiency $[117,118]$.

Promoting the aggregation of fullerene in polymer/fullerene blends is of benefit for the formation of an interpenetrating network. Heeger et al. prolonged the film-forming time of the [2,6-(4,4-bis(2-ethylhexyl)-4H-cyclopenta[2,1-b;3,4-b']-dithiophene)-alt-4,7-

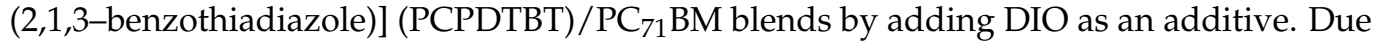
to the high b.p. and selective solubility for $\mathrm{PC}_{71} \mathrm{BM}$ of DIO, PCPDTBT precipitates in advance after the evaporation of the main solvent, while $\mathrm{PC}_{71} \mathrm{BM}$ is still dissolved in DIO. Consequently, the crystallization process of PCPDTBT and $\mathrm{PC}_{71} \mathrm{BM}$ occurs in different stages. Without the disturbance between the donor and acceptor and the prolonged filmforming process, it is easy for PCPDTBT and $\mathrm{PC}_{71} \mathrm{BM}$ to self-organize into continuous pathways [76]. In order to confirm the formation of a continuous structure, the authors 
removed the $\mathrm{PC}_{71} \mathrm{BM}$ in the blend film, as shown in Figure 15. It is obvious that the residual PCPDTBT formed an island-like phase separation structure without additives, while after adding DIO, continuous pathways formed due to the formation of PCPDTBT fibers, and the aggregated fullerene filled in the space between polymer fibers; thus, a bi-continuous structure was formed. The optimized phase separation structure was beneficial for the device performance, resulting in the increase in $J_{\mathrm{SC}}$ from $11.74 \mathrm{~mA} / \mathrm{cm}^{2}$ to $15.73 \mathrm{~mA} / \mathrm{cm}^{2}$ and the PCE from $3.35 \%$ to $5.12 \%$.

(a)

(c)
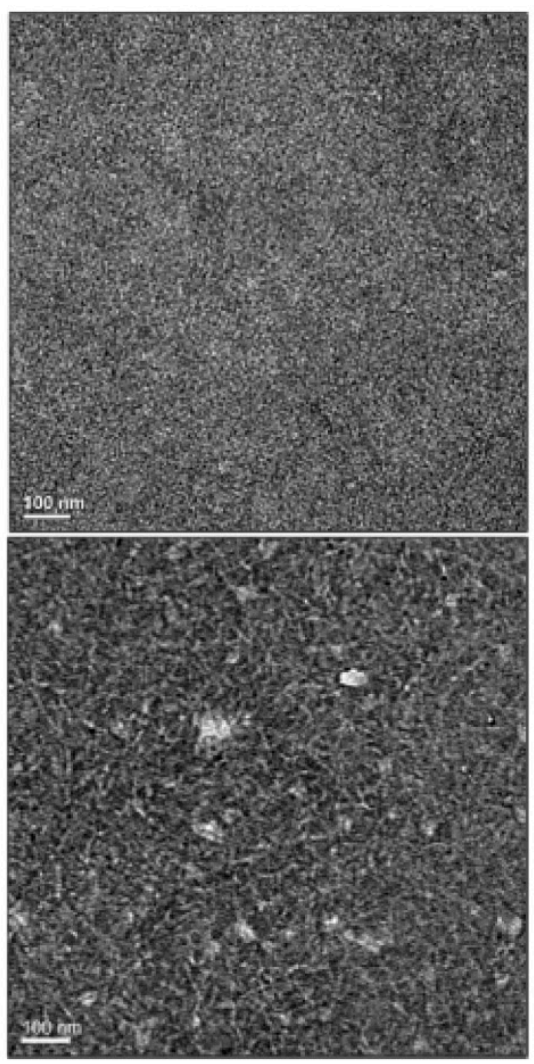

(b)

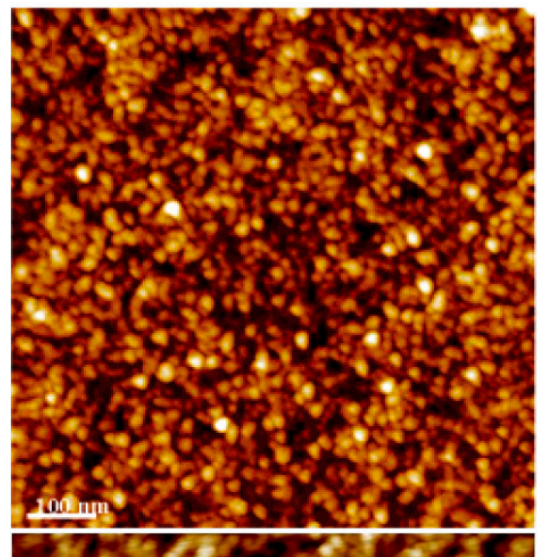

(d)

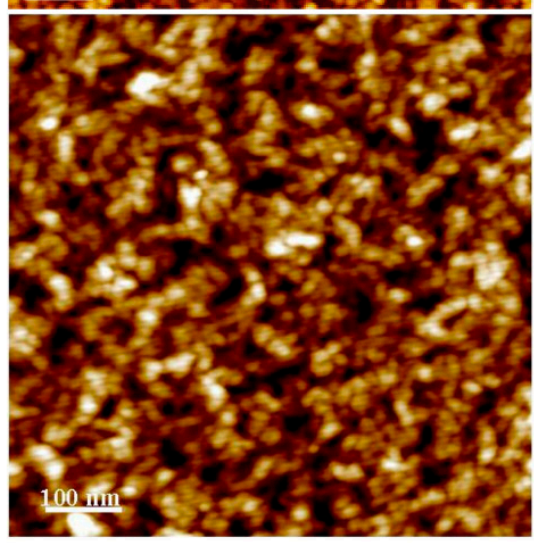

(e)

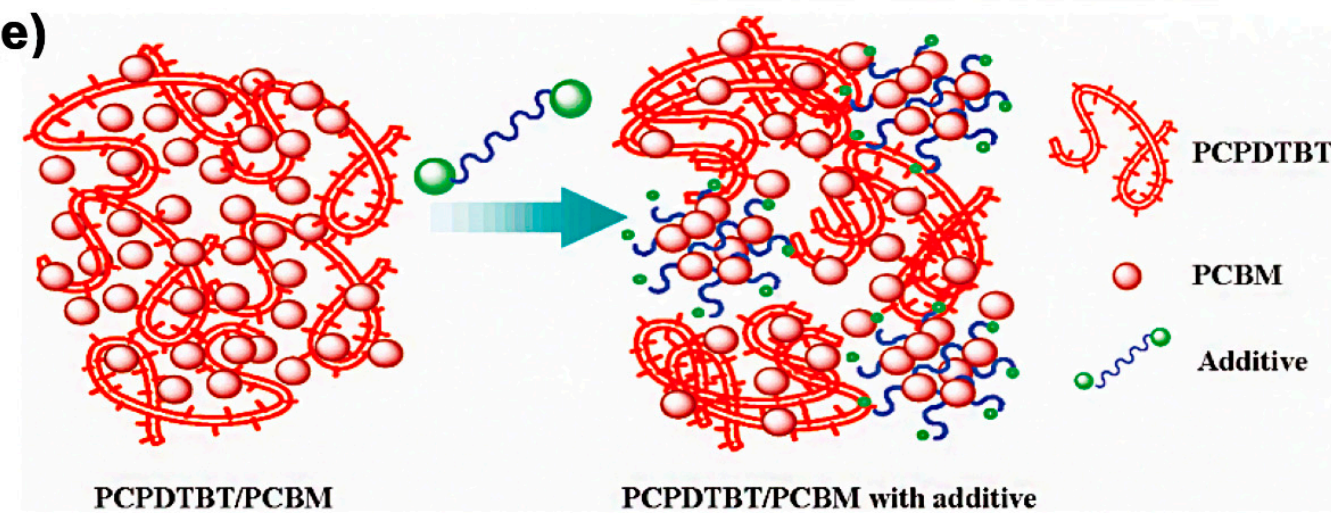

Figure 15. TEM image of PCPDTBT/PC 71 BM film (a) without and (c) with the addition of the 1,8-diiodooctane. AFM diagram of the PCPDTBT network structure after the removal of $\mathrm{PC}_{71} \mathrm{BM}$ film treated (b) without and (d) with 1,8-diiodooctane. (e) Schematic illumination of the action of the 1,8-diiodooctane in the self-assembly of bulk heterojunction blend materials. Reproduced from [76]. Reprinted with permission from ref. [76]. Copyright 2008 American Chemical Society.

The vertical phase separation structure could be optimized by the regulating filmforming process. Sun et al. [77] prolonged the film-forming process of the P3HT/PCBM blend by adding tetralin as an additive. As the $\mathrm{X}$-ray photoelectron spectroscopy (XPS) (Figure 16a,b) shows, the quality ratio of PCBM to P3HT ( $\left.m_{P C B M}: m_{P 3 H T}\right)$ near the film 
surface increased from 0.1 to 0.72 after adding $\mathrm{CN}$. This variation was ascribed to the high solubility of PCBM and slow volatilization rate of $\mathrm{CN}$ compared to the main solvent. At the late stage of the film-forming process, parts of PCBM dissolved in the residual CN. As $\mathrm{CN}$ evaporated, PCBM migrated from the inside to the surface of the film, driven by the directed diffusion of $\mathrm{CN}$. This kind of vertical phase separation is benefit for charge transport and collection of devices with normal structure. Thus, the PCE is 1.5 times higher than the device fabricated from the solution without $\mathrm{CN}$.

Combining the film-forming kinetics and surface tension is also an effective way to optimize the vertical phase separation. Liang et al. [42] added 1,2,4-triclorobenzene (TCB) to the CB solution of the P3HT / $\left.5 \mathrm{Z}, 5^{\prime} \mathrm{Z}\right)-5,5^{\prime}-\left(\left(7,7^{\prime}-(4,4,9,9-\right.\right.$ tetraoctyl-4,9-dihydro-sindaceno[1,2-b:5,6- $\left.\mathrm{b}^{\prime}\right]$ dithiophene-2,7-diyl)bis(benzo[c] [1,2,5]thiadiazole7,4diyl))bis(meth anylylidene))bis(3-ethyl-2-thioxothiazolidin-4-one) (O-IDTBR) blends to improve its vertical phase separation. After adding TCB, the content of P3HT near the top surface increased from $89 \%$ to $96 \%$, while the content of P3HT near the bottom of the film decreased from $50 \%$ to $42 \%$ according to depth-dependent absorption spectra as shown in Figure 16c. These variations can be interpreted by the differences in characters between CB and TCB, especially their b.p. and the solubility of solutes in them. Due to the lower surface tension of P3HT compared with PCBM $\left(\gamma_{P 3 H T}=21.1 \mathrm{mN} / \mathrm{m}<\gamma_{O-I D T B R}=28.1 \mathrm{mN} / \mathrm{m}\right)$, P3HT in the P3HT/PCBM blends is inclined to move to the top surface to decrease the Gibbs free energy during the film-forming process. When using $\mathrm{CB}$ as solvent, the film-forming process was $\sim 50 \mathrm{~s}$, and a large number of $\mathrm{P} 3 \mathrm{HT}$ did not have enough time to migrate. Therefore, the vertical phase separation was not thorough. After adding TCB, since TCB has a higher b.p. than the main solvent $C B$, the film-forming process was prolonged to $\sim 210 \mathrm{~s}$. Meanwhile, the solubility of P3HT and O-IDTBR in TCB was higher than that in CB. Hence, after the volatilization of $\mathrm{CB}$, a mass of P3HT and O-IDTBR still dissolved in TCB. As TCB evaporates, $\mathrm{P} 3 \mathrm{HT}$ has enough time to migrate, leading to more P3HT distributed on the top surface of film. The optimized morphology suppressed the bimolecular recombination (the exponential factor $\alpha$ increased from 0.96 to 0.98 ), boosting the PCE from $4.45 \%$ to $7.18 \%$ in an inverted device structure. A similar phenomenon was observed in polymer/fullerene blends as well. Yang et al. used DCB as main solvent and 1,8-octanedithiol (OT) as an additive in the P3HT/PCBM blend. The addition of OT increased the content of P3HT at the film surface and decreased the content of PCBM at the film bottom, as shown in Figure $16 \mathrm{~d}$, which increased PCE by 10 times from the initial $\sim 0.29 \%$. All the examples demonstrate that changing the film-forming kinetics to optimize the lateral and vertical phase separation structure of the active layer is an effective method to improve the device performance of OSCs.

Shao and co-workers reported using a PTB7-th:IEIC-4F blend system to study the effect of additives on morphology when PET/ITO, which is a stretchable substrate, was employed [119]. When $5 \mathrm{wt} \%$ PDMS was added to the blend with PET/ITO, compared to the PCE of $10.8 \%$ in the glass substrate system without additive, the PCE can be maintained at $10.3 \%$, and did not deteriorate the phase separation structure of the $\mathrm{BHJ}$ layer (Figure 17a-d). The illustration (Figure 17e) shows that PDMS can reduce the interchain interactions of the polymer and enhance the volume for polymer chain movement upon extrinsic strain. Due to the enhanced softness, the phase structure of active layer can be protected. 


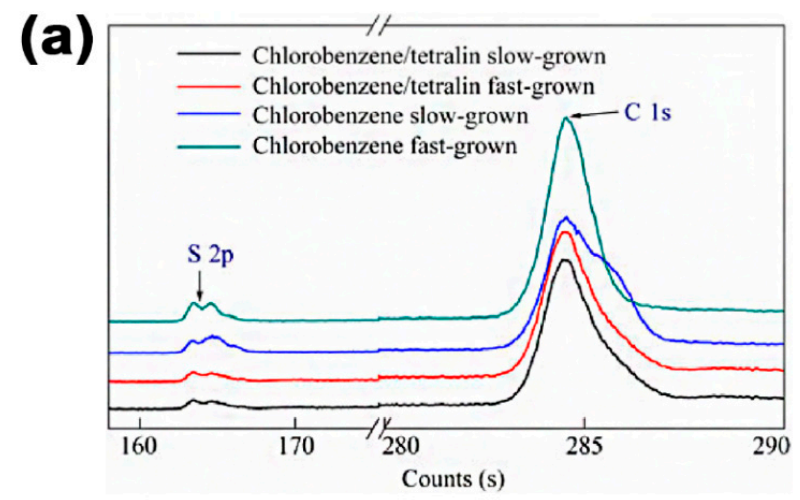

(b)

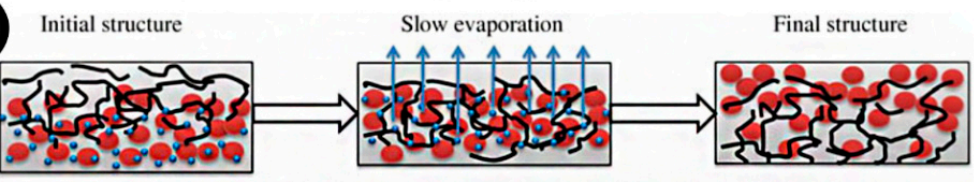

The second solvent evaporates slowly and drives PCBM to diffuse upwards

$\sim$ P3HT

- The second solvent with high boiling point and much better solubility of PCBM than P3HT
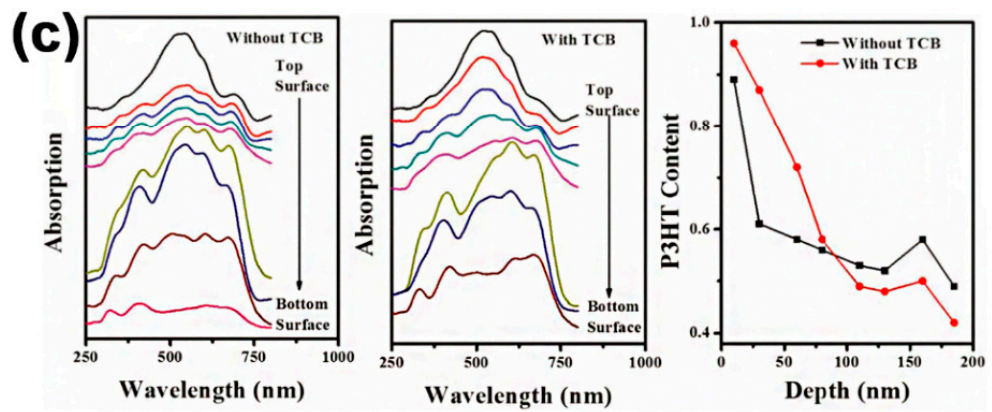

(d)
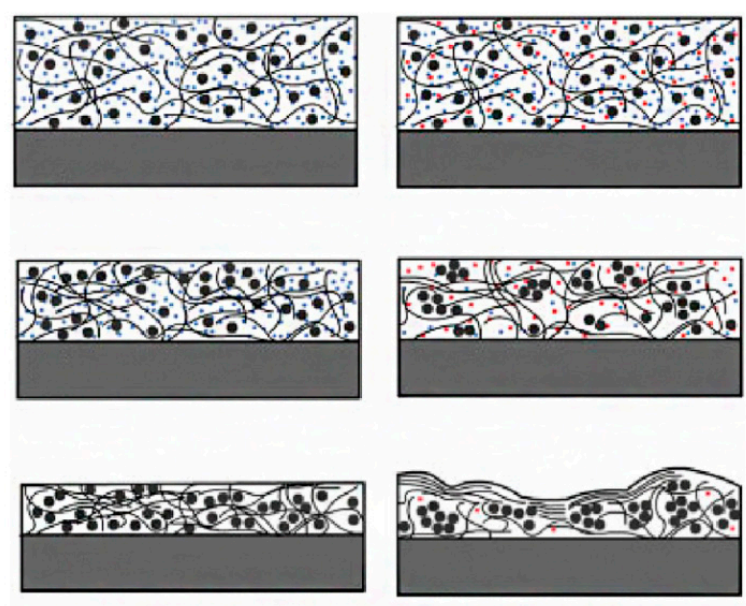

\section{Without OT}

With OT

Figure 16. (a) XPS spectrum. (b) Schematic of the role of solvent evaporation rate. Reproduced from [77]. (c) Film-depth-dependent light absorption spectra of P3HT:O-IDTBR blend film prepared under different conditions. Top and bottom surfaces represent $\mathrm{P} 3 \mathrm{HT}: \mathrm{O}-\mathrm{IDTBR} / \mathrm{MoO}_{3}$ and $\mathrm{ZnO} / \mathrm{P3HT}$ :O-IDTBR interfaces, respectively. Reproduced from [42]. Reprinted with permission from ref. [42]. Copyright 2019 Wiley; (d) Schematic diagram of morphology evolution in films treated with two types of solvent. Reproduced from [120]. Reprinted with permission from ref. [77]. Copyright 2013 Chinese Chemical Society; Reprinted with permission from ref. [120]. Copyright 2008 Wiley. 

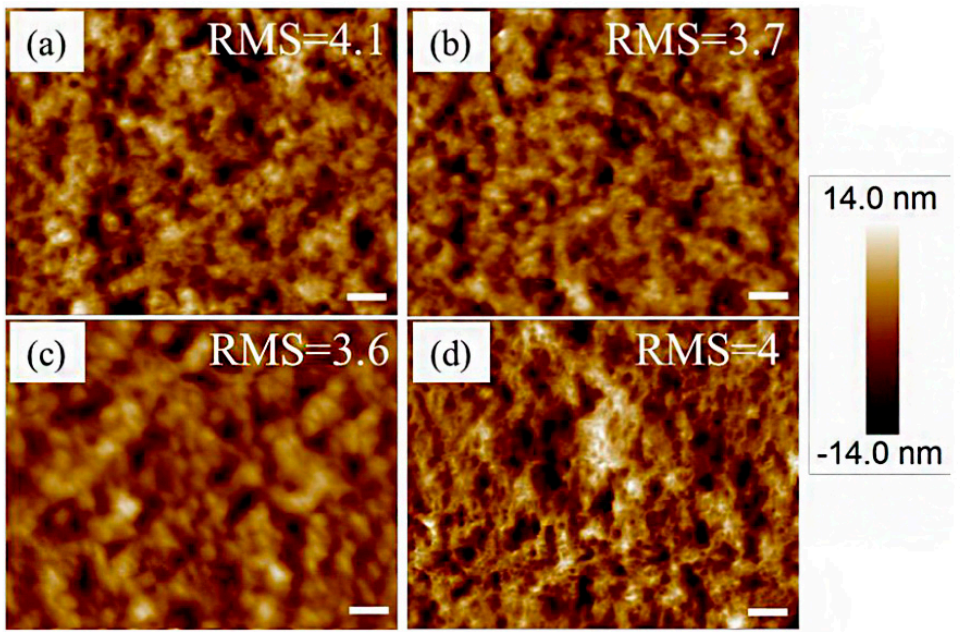

(e)

Crack
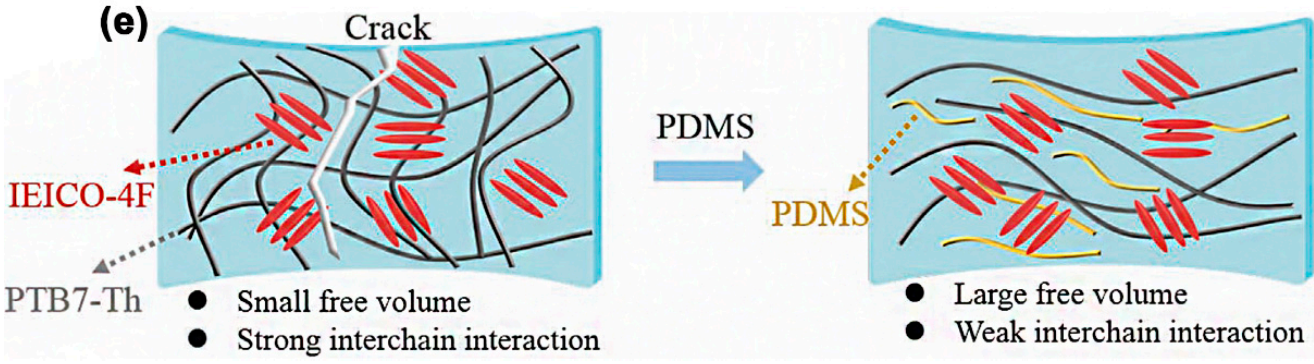

Figure 17. AFM height images of BHJ films with (a) $0 \mathrm{wt} \%$, (b) $5 \mathrm{wt} \%$, (c) $10 \mathrm{wt} \%$ and (d) $15 \mathrm{wt} \%$ PDMS contents (scale bar: $200 \mathrm{~nm}$ ). (e) Illustration of improved stretchability. Reproduced from [119]. Reprinted with permission from ref. [119]. Copyright 2021 Wiley.

\section{Summary and Perspectives}

The photovoltaic performance of OSCs is closely related to the BHJ morphology of the active layer, because the crystallinity, molecular orientation, domain size and phase separation structure have a profound influence on the exciton dissociation, charge transport and collection. We know that the morphology of $\mathrm{BHJ}$ is a kinetically frozen structure. Hence, regulating the duration of the film-forming process, including solvent engineering and adjusting the substrate temperature, is an effective way to optimize the morphology of the active layer. The film-forming process contains solvent evaporation and solutes solidification, thus regulating the b.p. of solvents and spinning rate, and so is effective at optimizing the morphology. Specifically, prolonging the film-forming process could extend the duration of molecular diffusion, which is of benefit for the crystallization and phase separation; thus, high crystallinity and a large domain size with high phase purity were achieved. Moreover, the shortening of the film-forming process could promote the molecules to stay in a metastable state, in which the molecules tend to adopt face-on orientation. Furthermore, the selective solubility and high b.p. of the additive could also regulate the sequence of solidification between the donor and acceptor, promoting the formation of interpenetrating networks with optimized lateral phase separation. Overall, the examples demonstrated herein offer a rational guide to understanding the foundation of film-forming kinetics for optimizing the $\mathrm{BHJ}$ morphology of the active layer.

Presently, OSCs based on polymer/nonfullerene blends dominate the development of OSCs. The morphology optimization of the nonfullerene-based blend films empirically follows the various treatments originally developed in polymer/fullerene blends. Considering the different properties between nonfullerene and fullerene derivatives, such as solubility in solvent, miscibility between donor and acceptor and molecular diffusivity, morphology optimization should pay comprehensive attention to the molecular properties of the active layer, and rational morphology control treatments should be developed toward the combined goal of improved efficiency and increased stability. Additionally, 
solvent engineering is able to meet the requirements for the practical application of OSCs, such as the fabrication of large-area and flexible OSCs. Hence, thorough comprehension of film-forming kinetics in non-halogenated additives during large-area film-forming process should be taken into account to fabricate OSCs for their future application. The other important point is that existing research on film-forming kinetics does not elaborate on the relationship between kinetics and intermixed phases; although the study of intermixed phases is very complicated, kinetics may be used as a method to explore this field in the future.

Author Contributions: Conceptualization, Q.L. and J.Y.; methodology, J.L.; software, Z.H.; validation, P.W., Y.Y., K.W. and H.L.; formal analysis, Q.L.; investigation, J.Y.; resources, J.L.; data curation, Q.L.; writing—original draft preparation, J.Y.; writing—review and editing, Q.L.; visualization, J.L.; supervision, Q.L.; project administration, J.Y.; funding acquisition, J.L. All authors have read and agreed to the published version of the manuscript.

Funding: This work was supported by the National Natural Science Foundation of China (51773203, 51903211, 52073231), the Fundamental Research Funds for the Central Universities (D5000200273, D5000210689), the China Postdoctoral Science Foundation (2020T130535, 2020M673468), the National Aerospace Science Foundation of China (2020Z073053010) and Natural Science Foundation of Chongqing, China (cstc2021jcyj-msxmX0990).

Institutional Review Board Statement: Not applicable.

Informed Consent Statement: Not applicable.

Data Availability Statement: Not applicable.

Acknowledgments: This work was supported by the National Natural Science Foundation of China (51773203, 51903211, 52073231), the Fundamental Research Funds for the Central Universities (D5000200273, D5000210689), the China Postdoctoral Science Foundation (2020T130535, 2020M673468), the National Aerospace Science Foundation of China (2020Z073053010) and Natural Science Foundation of Chongqing, China (cstc2021jcyj-msxmX0990).

Conflicts of Interest: The authors declare no conflict of interest.

\section{References}

1. Servaites, J.D.; Ratner, M.A.; Marks, T.J. Organic solar cells: A new look at traditional models. Energy Environ. Sci. 2011, 4, 4410-4422. [CrossRef]

2. Service, R.F. Solar energy. Outlook brightens for plastic solar cells. Science 2011, 332, 293. [CrossRef] [PubMed]

3. Dou, L.; You, J.; Hong, Z.; Xu, Z.; Li, G.; Street, R.A.; Yang, Y. 25th anniversary article: A decade of organic/polymeric photovoltaic research. Adv. Mater. 2013, 25, 6642-6671. [CrossRef] [PubMed]

4. Krebs, F.C.; Espinosa, N.; Hosel, M.; Sondergaard, R.R.; Jorgensen, M. 25th anniversary article: Rise to power--OPV-based solar parks. Adv. Mater. 2014, 26, 29-38. [CrossRef] [PubMed]

5. Liu, Q.; Jiang, Y.; Jin, K.; Qin, J.; Xu, J.; Li, W.; Xiong, J.; Liu, J.; Xiao, Z.; Sun, K.; et al. 18\% Efficiency organic solar cells. Sci. Bull. 2020, 65, 272-275. [CrossRef]

6. Song, J.; Zhu, L.; Li, C.; Xu, J.; Wu, H.; Zhang, X.; Zhang, Y.; Tang, Z.; Liu, F.; Sun, Y. High-efficiency organic solar cells with low voltage loss induced by solvent additive strategy. Matter 2021, 4, 2542-2552. [CrossRef]

7. Meng, H.; Liao, C.; Deng, M.; Xu, X.; Yu, L.; Peng, Q. 18.77\% Efficiency Organic Solar Cells Promoted by Aqueous Solution Processed Cobalt(II) Acetate Hole Transporting Layer. Angew. Chem. Int. Ed. 2021, 60, 22554-22561. [CrossRef]

8. Liu, L.; Chen, S.; Qu, Y.; Gao, X.; Han, L.; Lin, Z.; Yang, L.; Wang, W.; Zheng, N.; Liang, Y.; et al. Nanographene-Osmapentalyne Complexes as a Cathode Interlayer in Organic Solar Cells Enhance Efficiency over 18. Adv. Mater. 2021, 33, e2101279. [CrossRef]

9. Liu, G.; Xia, R.; Huang, Q.; Zhang, K.; Hu, Z.; Jia, T.; Liu, X.; Yip, H.L.; Huang, F. Tandem Organic Solar Cells with 18.7\% Efficiency Enabled by Suppressing the Charge Recombination in Front Sub-Cell. Adv. Funct. Mater. 2021, 31, 2103283. [CrossRef]

10. Li, C.; Zhou, J.; Song, J.; Xu, J.; Zhang, H.; Zhang, X.; Guo, J.; Zhu, L.; Wei, D.; Han, G.; et al. Non-fullerene acceptors with branched side chains and improved molecular packing to exceed 18\% efficiency in organic solar cells. Nat. Energy 2021, 6, 605-613. [CrossRef]

11. Jin, K.; Xiao, Z.; Ding, L. 18.69\% PCE from organic solar cells. J. Semicond. 2021, 42, 060502. [CrossRef]

12. Guo, C.; Li, D.; Wang, L.; Du, B.; Liu, Z.X.; Shen, Z.; Wang, P.; Zhang, X.; Cai, J.; Cheng, S.; et al. Cold-Aging and Solvent Vapor Mediated Aggregation Control toward 18\% Efficiency Binary Organic Solar Cells. Adv. Energy Mater. 2021, 11, 2102000. [CrossRef] 
13. Zhang, T.; An, C.; Bi, P.; Lv, Q.; Qin, J.; Hong, L.; Cui, Y.; Zhang, S.; Hou, J. A Thiadiazole-Based Conjugated Polymer with Ultradeep HOMO Level and Strong Electroluminescence Enables 18.6\% Efficiency in Organic Solar Cell. Adv. Energy Mater. 2021, 11, 2101705. [CrossRef]

14. Liu, F.; Zhou, L.; Liu, W.; Zhou, Z.; Yue, Q.; Zheng, W.; Sun, R.; Liu, W.; Xu, S.; Fan, H.; et al. Organic Solar Cells with 18\% Efficiency Enabled by an Alloy Acceptor: A Two-in-One Strategy. Adv. Mater. 2021, 33, 2100830. [CrossRef]

15. Lin, Y.; Magomedov, A.; Firdaus, Y.; Kaltsas, D.; El-Labban, A.; Faber, H.; Naphade, D.R.; Yengel, E.; Zheng, X.; Yarali, E.; et al. $18.4 \%$ Organic Solar Cells Using a High Ionization Energy Self-Assembled Monolayer as Hole-Extraction Interlayer. ChemSusChem 2021, 14, 3569-3578. [CrossRef]

16. Li, Y.; Cai, Y.H.; Xie, Y.P.; Song, J.H.; Wu, H.B.; Tang, Z.; Zhang, J.; Huang, F.; Sun, Y.M. A facile strategy for third-component selection in non-fullerene acceptor-based ternary organic solar cells. Energy Environ. Sci. 2021, 14, 5009-5016. [CrossRef]

17. Cui, Y.; Xu, Y.; Yao, H.; Bi, P.; Hong, L.; Zhang, J.; Zu, Y.; Zhang, T.; Qin, J.; Ren, J.; et al. Single-Junction Organic Photovoltaic Cell with 19\% Efficiency. Adv. Mater. 2021, 33, 2102420. [CrossRef] [PubMed]

18. Chen, X.; Wang, D.; Wang, Z.; Li, Y.; Zhu, H.; Lu, X.; Chen, W.; Qiu, H.; Zhang, Q. 18.02\% Efficiency ternary organic solar cells with a small-molecular donor third component. Chem. Eng. J. 2021, 424, 130397. [CrossRef]

19. Cai, Y.; Li, Y.; Wang, R.; Wu, H.; Chen, Z.; Zhang, J.; Ma, Z.; Hao, X.; Zhao, Y.; Zhang, C.; et al. A Well-Mixed Phase Formed by Two Compatible Non-Fullerene Acceptors Enables Ternary Organic Solar Cells with Efficiency over 18.6\%. Adv. Mater. 2021, 33, 2101733. [CrossRef] [PubMed]

20. Mazzio, K.A.; Luscombe, C.K. The future of organic photovoltaics. Chem. Soc. Rev. 2015, 44, 78-90. [CrossRef]

21. Hood, S.N.; Kassal, I. Entropy and Disorder Enable Charge Separation in Organic Solar Cells. J. Phys. Chem. Lett. 2016, 7, 4495-4500. [CrossRef] [PubMed]

22. Scharber, M.C.; Sariciftci, N.S. Efficiency of bulk-heterojunction organic solar cells. Prog. Polym. Sci. 2013, 38, 1929-1940. [CrossRef]

23. Gülen, D. Determination of the exciton diffusion length by surface quenching experiments. J. Lumin. 1988, 42, 191-195. [CrossRef]

24. Hong, N.H.; Sakai, J.; Huong, N.T.; Poirot, N.; Ruyter, A. Role of defects in tuning ferromagnetism in diluted magnetic oxide thin films. Phys. Rev. B 2005, 72, 045336. [CrossRef]

25. Zhang, R.; Yang, H.; Zhou, K.; Zhang, J.; Liu, J.; Yu, X.; Xing, R.; Han, Y. Optimized domain size and enlarged D/A interface by tuning intermolecular interaction in all-polymer ternary solar cells. J. Polym. Sci. Part B Polym. Phys. 2016, 54, 1811-1819. [CrossRef]

26. Chen, S.; Zhang, L.; Ma, C.; Meng, D.; Zhang, J.; Zhang, G.; Li, Z.; Chow, P.C.Y.; Ma, W.; Wang, Z.; et al. Alkyl Chain Regiochemistry of Benzotriazole-Based Donor Polymers Influencing Morphology and Performances of Non-Fullerene Organic Solar Cells. Adv. Energy Mater. 2018, 8, 1702427. [CrossRef]

27. Zhou, K.; Zhao, Q.; Zhang, R.; Cao, X.; Yu, X.; Liu, J.; Han, Y. Decreased domain size of p-DTS(FBTTh 2$)_{2} /$ P(NDI2OD-T2) blend films due to their different solution aggregation behavior at different temperatures. Phys. Chem. Chem. Phys. 2017, 19, 32373-32380. [CrossRef]

28. Xiao, B.; Du, M.; Wang, X.; Xiao, Z.; Li, G.; Tang, A.; Ding, L.; Geng, Y.; Sun, X.; Zhou, E. Effects of Oxygen Atoms Introduced at Different Positions of Non-Fullerene Acceptors in the Performance of Organic Solar Cells with Poly(3-hexylthiophene). ACS Appl. Mater. Interfaces 2020, 12, 1094-1102. [CrossRef]

29. Zhou, K.; Wu, Y.; Liu, Y.F.; Zhou, X.B.; Zhang, L.; Ma, W. Molecular Orientation of Polymer Acceptor Dominates Open-Circuit Voltage Losses in All-Polymer Solar Cells. ACS Energy Lett. 2019, 4, 1057-1064. [CrossRef]

30. Rand, B.P.; Cheyns, D.; Vasseur, K.; Giebink, N.C.; Mothy, S.; Yi, Y.; Coropceanu, V.; Beljonne, D.; Cornil, J.; Brédas, J.-L.; et al. The Impact of Molecular Orientation on the Photovoltaic Properties of a Phthalocyanine/Fullerene Heterojunction. Adv. Funct. Mater. 2012, 22, 2987-2995. [CrossRef]

31. Zhang, Q.; Xiao, B.; Du, M.; Li, G.; Tang, A.; Zhou, E. A2-A1-D-A1-A2 type non-fullerene acceptors based on methoxy substituted benzotriazole with three different end-capped groups for P3HT-based organic solar cells. J. Mater. Chem. C 2018, 6, 10902-10909. [CrossRef]

32. Xiao, B.; Tang, A.; Zhang, J.; Mahmood, A.; Wei, Z.; Zhou, E. Achievement of High $\mathrm{V}_{\text {oc }}$ of 1.02 V for P3HT-Based Organic Solar Cell Using a Benzotriazole-Containing Non-Fullerene Acceptor. Adv. Energy Mater. 2017, 7, 1602269. [CrossRef]

33. Qiu, N.L.; Yang, X.; Zhang, H.J.; Wan, X.J.; Li, C.X.; Liu, F.; Zhang, H.T.; Russell, T.P.; Chen, Y.S. Nonfullerene Small Molecular Acceptors with a Three-Dimensional (3D) Structure for Organic Solar Cells. Chem. Mater. 2016, 28, 6770-6778. [CrossRef]

34. Liang, Q.; Han, J.; Song, C.; Yu, X.; Smilgies, D.-M.; Zhao, K.; Liu, J.; Han, Y. Reducing the confinement of PBDB-T to ITIC to improve the crystallinity of PBDB-T/ITIC blends. J. Mater. Chem. A 2018, 6, 15610-15620. [CrossRef]

35. Liu, J.; Zeng, S.; Zhang, Z.; Peng, J.; Liang, Q. Optimizing the Phase-Separated Domain Size of the Active Layer via Sequential Crystallization in All-Polymer Solar Cells. J. Phys. Chem. Lett. 2020, 11, 2314-2321. [CrossRef]

36. Xu, X.; Zhang, G.; Yu, L.; Li, R.; Peng, Q. P3HT-Based Polymer Solar Cells with 8.25\% Efficiency Enabled by a Matched Molecular Acceptor and Smart Green-Solvent Processing Technology. Adv. Mater. 2019, 31, 1906045. [CrossRef] [PubMed]

37. Yang, C.; Yu, R.; Liu, C.; Li, H.; Zhang, S.; Hou, J. Achieving over 10 \% Efficiency in Poly(3-hexylthiophene)-based Organic Solar Cells via Solid Additives. ChemSusChem 2021, 14, 3607-3613. [CrossRef]

38. Liu, F.; Zhang, J.Y.; Zhou, Z.C.; Zhang, J.Q.; Wei, Z.X.; Zhu, X.Z. Poly(3-hexylthiophene)-based non-fullerene solar cells achieve high photovoltaic performance with small energy loss. J. Mater. Chem. A 2017, 5, 16573-16579. [CrossRef] 
39. Li, S.; Liu, W.; Shi, M.; Mai, J.; Lau, T. -K.; Wan, J.; Lu, X.; Li, C.-Z.; Chen, H. A spirobifluorene and diketopyrrolopyrrole moieties based non-fullerene acceptor for efficient and thermally stable polymer solar cells with high open-circuit voltage. Energy Environ. Sci. 2016, 9, 604-610. [CrossRef]

40. Holliday, S.; Ashraf, R.S.; Wadsworth, A.; Baran, D.; Yousaf, S.A.; Nielsen, C.B.; Tan, C.H.; Dimitrov, S.D.; Shang, Z.; Gasparini, N.; et al. High-efficiency and air-stable P3HT-based polymer solar cells with a new non-fullerene acceptor. Nat. Commun. 2016, 7 , 11585. [CrossRef]

41. Liu, J.G.; Zeng, S.Y.; Jing, P.; Zhao, K.; Liang, Q.J. Investigating the effect of cosolvents on P3HT/O-IDTBR film-forming kinetics and film morphology. J. Energy. Chem. 2020, 51, 333-341. [CrossRef]

42. Liang, Q.; Jiao, X.; Yan, Y.; Xie, Z.; Lu, G.; Liu, J.; Han, Y. Separating Crystallization Process of P3HT and O-IDTBR to Construct Highly Crystalline Interpenetrating Network with Optimized Vertical Phase Separation. Adv. Funct. Mater. 2019, 29 , 1807591. [CrossRef]

43. Gaspar, H.; Figueira, F.; Pereira, L.; Mendes, A.; Viana, J.C.; Bernardo, G. Recent Developments in the Optimization of the Bulk Heterojunction Morphology of Polymer: Fullerene Solar Cells. Materials 2018, 11, 2560. [CrossRef] [PubMed]

44. Wang, X.; Sun, Q.; Gao, J.; Wang, J.; Xu, C.; Ma, X.; Zhang, F. Recent Progress of Organic Photovoltaics with Efficiency over 17\%. Energies 2021, 14, 4200. [CrossRef]

45. Liao, K.-S.; Yambem, S.D.; Haldar, A.; Alley, N.J.; Curran, S.A. Designs and Architectures for the Next Generation of Organic Solar Cells. Energies 2010, 3, 1212-1250. [CrossRef]

46. Zhao, Y.; Yuan, G.X.; Roche, P.; Leclerc, M. A Calorimetric Study of the Phase-Transitions in Poly(3-Hexylthiophene). Polymer 1995, 36, 2211-2214. [CrossRef]

47. Dittmer, J.J.; Lazzaroni, R.; Leclere, P.; Moretti, P.; Granstrom, M.; Petritsch, K.; Marseglia, E.A.; Friend, R.H.; Bredas, J.L.; Rost, H.; et al. Crystal network formation in organic solar cells. Sol. Energy Mater Sol. Cells 2000, 61, 53-61. [CrossRef]

48. Padinger, F.; Rittberger, R.S.; Sariciftci, N.S. Effects of postproduction treatment on plastic solar cells. Adv. Funct. Mater. 2003, 13, 85-88. [CrossRef]

49. Jenekhe, S.A.; Yi, S.J. Highly photoconductive nanocomposites of metallophthalocyanines and conjugated polymers. Adv. Mater. 2000, 12, 1274. [CrossRef]

50. Ma, W.; Yang, C.; Gong, X.; Lee, K.; Heeger, A.J. Thermally Stable, Efficient Polymer Solar Cells with Nanoscale Control of the Interpenetrating Network Morphology. Adv. Funct. Mater. 2005, 15, 1617-1622. [CrossRef]

51. Lee, H.; Oh, S.; Song, C.E.; Lee, H.K.; Lee, S.K.; Shin, W.S.; So, W.W.; Moon, S.J.; Lee, J.C. Stable P3HT: Amorphous non-fullerene solar cells with a high open-circuit voltage of $1 \mathrm{~V}$ and efficiency of 4\%. RSC Adv. 2019, 9, 20733-20741. [CrossRef]

52. Jang, M.; Huh, Y.I.; Chang, M. Effects of Solvent Vapor Annealing on Morphology and Charge Transport of Poly(3-hexylthiophene) (P3HT) Films Incorporated with Preformed P3HT Nanowires. Polymers 2020, 12, 1188. [CrossRef]

53. Li, G.; Shrotriya, V.; Huang, J.; Yao, Y.; Moriarty, T.; Emery, K.; Yang, Y. High-efficiency solution processable polymer photovoltaic cells by self-organization of polymer blends. Nat. Mater. 2005, 4, 864-868. [CrossRef]

54. Wu, J.; Yuan, Y.; Gao, M.; Wang, Z.; Jiang, L. Preparation of Single Crystals of Small Molecule Organic Semiconductor via Solvent Vapor Annealing. Acta Chim. Sin. 2015, 73, 23-28. [CrossRef]

55. Vogelsang, J.; Brazard, J.; Adachi, T.; Bolinger, J.C.; Barbara, P.F. Watching the Annealing Process One Polymer Chain at a Time. Angew. Chem. Int. Ed. 2011, 50, 2257-2261. [CrossRef]

56. Hammed, W.; Yahya, R.; Bola, A.u.; Mahmud, H. Recent Approaches to Controlling the Nanoscale Morphology of Polymer-Based Bulk-Heterojunction Solar Cells. Energies 2013, 6, 5847-5868. [CrossRef]

57. Yang, L.; Zhang, S.; He, C.; Zhang, J.; Yao, H.; Yang, Y.; Zhang, Y.; Zhao, W.; Hou, J. New Wide Band Gap Donor for Efficient Fullerene-Free All-Small-Molecule Organic Solar Cells. J. Am. Chem. Soc. 2017, 139, 1958-1966. [CrossRef]

58. Chang, Y.M.; Wang, L. Efficient Poly(3-hexylthiophene)-Based Bulk Heterojunction Solar Cells Fabricated by an Annealing-Free Approach. J. Phys. Chem. C 2008, 112, 17716-17720. [CrossRef]

59. Berson, S.; De Bettignies, R.; Bailly, S.; Guillerez, S. Poly(3-hexylthiophene) Fibers for Photovoltaic Applications. Adv. Funct. Mater. 2007, 17, 1377-1384. [CrossRef]

60. Yang, D.; Yu, K.; Xu, J.; Zhang, J.; Zhang, J.; Gao, J.; Song, W.; Li, D.; Chen, Z.; Ge, Z. Achieving 10\% efficiency in non-fullerene all-small-molecule organic solar cells without extra treatments. J. Mater. Chem. A 2021, 9, 10427-10436. [CrossRef]

61. Wan, J.; Wen, R.; Xia, Y.; Dai, M.; Huang, H.; Xue, L.; Zhang, Z.; Fang, J.; Hui, K.N.; Fan, X. All annealing-free solution-processed highly flexible organic solar cells. J. Mater. Chem. A 2021, 9, 5425-5433. [CrossRef]

62. Kazerouni, N.; Melenbrink, E.L.; Das, P.; Thompson, B.C. Ternary Blend Organic Solar Cells Incorporating Ductile Conjugated Polymers with Conjugation Break Spacers. ACS Appl. Polym. Mater. 2021, 3, 3028-3037. [CrossRef]

63. Avalos-Quiroz, Y.A.; Bardagot, O.; Kervella, Y.; Aumaitre, C.; Cabau, L.; Rivaton, A.; Margeat, O.; Videlot-Ackermann, C.; Vongsaysy, U.; Ackermann, J.; et al. Non-Fullerene Acceptors with an Extended pi-Conjugated Core: Third Components in Ternary Blends for High-Efficiency, Post-Treatment-Free Organic Solar Cells. ChemSusChem 2021, 14, 3502-3510. [CrossRef] [PubMed]

64. Buss, F.; Schmidt-Hansberg, B.; Sanyal, M.; Munuera, C.; Scharfer, P.; Schabel, W.; Barrena, E. Gaining Further Insight into the Solvent Additive-Driven Crystallization of Bulk-Heterojunction Solar Cells by in Situ X-ray Scattering and Optical Reflectometry. Macromolecules 2016, 49, 4867-4874. [CrossRef] 
65. Park, S.H.; Jin, I.S.; Ahn, H.; Jung, J.W. Non-halogenated additive engineering for morphology optimization in environmentalfriendly solvent processed non-fullerene organic solar cells. Org. Electron. 2020, 86, 105893. [CrossRef]

66. Kırbıyık Kurukavak, Ç.; Yılmaz, T.; Çetin, S..; Alqadasi, M.M.; Al-Khawlany, K.M.; Kuş, M. Synthesis of boron-doped CQDs and its use as an additive in P3HT:PCBM layer for efficiency improvement of organic solar cell. Microelectron. Eng. 2021, $235,111465$. [CrossRef]

67. Arbab, E.A.A.; Gebremichael, B.; Kumar, A.; Mola, G.T. Morphology-dependent performance of thin film organic solar cells. J. Mod. Opt. 2018, 66, 399-406. [CrossRef]

68. Alam, S.; Islam, M.M.; Chowdhury, S.; Meitzner, R.; Kästner, C.; Schubert, U.S.; Hoppe, H. Disentanglement of Degradation Mechanisms by Analyzing Aging Dynamics of Environmentally Friendly Processed Polymer Solar Cells. Energy Technol. 2020, 8 , 2000116. [CrossRef]

69. Shin, N.; Richter, L.J.; Herzing, A.A.; Kline, R.J.; DeLongchamp, D.M. Effect of Processing Additives on the Solidification of Blade-Coated Polymer/Fullerene Blend Films via In-Situ Structure Measurements. Adv. Energy Mater. 2013, 3, 938-948. [CrossRef]

70. Zhu, L.; Zhong, W.; Qiu, C.; Lyu, B.; Zhou, Z.; Zhang, M.; Song, J.; Xu, J.; Wang, J.; Ali, J.; et al. Aggregation-Induced Multilength Scaled Morphology Enabling 11.76\% Efficiency in All-Polymer Solar Cells Using Printing Fabrication. Adv. Mater. 2019, 31, 1902899. [CrossRef]

71. Li, W.; Chen, M.; Zhang, Z.; Cai, J.; Zhang, H.; Gurney, R.S.; Liu, D.; Yu, J.; Tang, W.; Wang, T. Retarding the Crystallization of a Nonfullerene Electron Acceptor for High-Performance Polymer Solar Cells. Adv. Funct. Mater. 2018, 29, 1807662. [CrossRef]

72. Zhou, K.; Zhang, R.; Liu, J.; Li, M.; Yu, X.; Xing, R.; Han, Y. Donor/Acceptor Molecular Orientation-Dependent Photovoltaic Performance in All-Polymer Solar Cells. ACS Appl. Mater. Interfaces 2015, 7, 25352-25361. [CrossRef] [PubMed]

73. Li, M.; Zhou, Y.; Yang, L.; Shen, S.; Liu, Y.; Chen, Y.; Song, J.; Bo, Z. Regulating molecular orientations of dipyran-based nonfullerene acceptors through side-chain engineering at the $\pi$-bridge. J. Mater. Chem. A 2020, 8, 22416-22422. [CrossRef]

74. Lee, C.; Li, Y.; Lee, W.; Lee, Y.; Choi, J.; Kim, T.; Wang, C.; Gomez, E.D.; Woo, H.Y.; Kim, B.J. Correlation between Phase-Separated Domain Sizes of Active Layer and Photovoltaic Performances in All-Polymer Solar Cells. Macromolecules 2016, 49, 5051-5058. [CrossRef]

75. Chen, J.; Bi, Z.; Xu, X.; Zhang, Q.; Yang, S.; Guo, S.; Yan, H.; You, W.; Ma, W. Fine Optimization of Morphology Evolution Kinetics with Binary Additives for Efficient Non-Fullerene Organic Solar Cells. Adv. Sci. 2019, 6, 1801560. [CrossRef]

76. Lee, J.K.; Ma, W.L.; Brabec, C.J.; Yuen, J.; Moon, J.S.; Kim, J.Y.; Lee, K.; Bazan, G.C.; Heeger, A.J. Processing Additives for Improved Efficiency from Bulk Heterojunction Solar Cells. J. Am. Chem. Soc. 2008, 130, 3619-3623. [CrossRef] [PubMed]

77. Sun, Y.; Liu, J.-G.; Ding, Y.; Han, Y.-C. Controlling the surface composition of PCBM in P3HT/PCBM blend films by using mixed solvents with different evaporation rates. Chin. J. Polym. Sci. 2013, 31, 1029-1037. [CrossRef]

78. Ye, L.; Hu, H.; Ghasemi, M.; Wang, T.; Collins, B.A.; Kim, J.H.; Jiang, K.; Carpenter, J.H.; Li, H.; Li, Z.; et al. Quantitative relations between interaction parameter, miscibility and function in organic solar cells. Nat. Mater. 2018, 17, 253-260. [CrossRef]

79. Raj Mohan, S.; Singh, M.P.; Joshi, M.P. A Model for Charge Transport in Semicrystalline Polymer Thin Films. J. Polym. Sci. Part B Polym. Phys. 2019, 57, 137-141. [CrossRef]

80. Ferron, T.; Waldrip, M.; Pope, M.; Collins, B.A. Increased charge transfer state separationviareduced mixed phase interface in polymer solar cells. J. Mater. Chem. A 2019, 7, 4536-4548. [CrossRef]

81. Fanta, G.M.; Jarka, P.; Szeluga, U.; Tanski, T.; Kim, J.Y. Phase Behavior of Amorphous/Semicrystalline Conjugated Polymer Blends. Polymers 2020, 12, 1726. [CrossRef]

82. Gu, K.; Wang, Y.; Li, R.; Tsai, E.; Onorato, J.W.; Luscombe, C.K.; Priestley, R.D.; Loo, Y.L. Role of Postdeposition Thermal Annealing on Intracrystallite and Intercrystallite Structuring and Charge Transport in Poly(3-hexylthiophene). ACS Appl. Mater. Interfaces 2021, 13, 999-1007. [CrossRef]

83. Liang, Q.J.; Hu, Z.B.; Yao, J.H.; Yin, Y.K.; Wei, P.X.; Chen, Z.K.; Li, W.C.; Liu, J.G. Recent advances in intermixed phase of organic solar cells: Characterization, regulating strategies and device applications. J. Polym. Sci. 2021, 1-28. [CrossRef]

84. Liang, Q.J.; Hu, Z.B.; Yao, J.H.; Wu, Z.H.; Ding, Z.C.; Zhao, K.; Jiao, X.C.; Liu, J.G.; Huang, W. Blending Donors with Different Molecular Weights: An Efficient Strategy to Resolve the Conflict between Coherence Length and Intermixed Phase in Polymer/Nonfullerene Solar Cells. Small 2021. [CrossRef]

85. Turner, S.T.; Pingel, P.; Steyrleuthner, R.; Crossland, E.J.W.; Ludwigs, S.; Neher, D. Quantitative Analysis of Bulk Heterojunction Films Using Linear Absorption Spectroscopy and Solar Cell Performance. Adv. Funct. Mater. 2011, 21, 4640-4652. [CrossRef]

86. Landi, G.; Barone, C.; Mauro, C.; De Sio, A.; Carapella, G.; Neitzert, H.; Pagano, S. Probing Temperature-Dependent Recombination Kinetics in Polymer:Fullerene Solar Cells by Electric Noise Spectroscopy. Energies 2017, 10, 1490. [CrossRef]

87. Engmann, S.; Bokel, F.A.; Ro, H.W.; DeLongchamp, D.M.; Richter, L.J. Real-Time Photoluminescence Studies of Structure Evolution in Organic Solar Cells. Adv. Energy Mater. 2016, 6, 1502011. [CrossRef]

88. Sim, M.; Shin, J.; Shim, C.; Kim, M.; Jo, S.B.; Kim, J.-H.; Cho, K. Dependence of Exciton Diffusion Length on Crystalline Order in Conjugated Polymers. J. Phys. Chem. C 2014, 118, 760-766. [CrossRef]

89. Burkhard, G.F.; Hoke, E.T.; Scully, S.R.; McGehee, M.D. Incomplete exciton harvesting from fullerenes in bulk heterojunction solar cells. Nano Lett. 2009, 9, 4037-4041. [CrossRef] [PubMed] 
90. Richter, L.J.; DeLongchamp, D.M.; Bokel, F.A.; Engmann, S.; Chou, K.W.; Amassian, A.; Schaible, E.; Hexemer, A. In Situ Morphology Studies of the Mechanism for Solution Additive Effects on the Formation of Bulk Heterojunction Films. Adv. Energy Mater. 2015, 5, 1400975. [CrossRef]

91. McDowell, C.; Abdelsamie, M.; Zhao, K.; Smilgies, D.M.; Bazan, G.C.; Amassian, A. Synergistic Impact of Solvent and Polymer Additives on the Film Formation of Small Molecule Blend Films for Bulk Heterojunction Solar Cells. Adv. Energy Mater. 2015, 5, 1501121. [CrossRef]

92. Zhou, R.; Jiang, Z.; Shi, Y.; Wu, Q.; Yang, C.; Zhang, J.; Lu, K.; Wei, Z. Moving Alkyl-Chain Branching Point Induced a Hierarchical Morphology for Efficient All-Small-Molecule Organic Solar Cells. Adv. Funct. Mater. 2020, 30, 2005426. [CrossRef]

93. Yu, Q.; Xu, J.; Fu, J.; Xu, T.; Yan, X.; Chen, S.; Chen, H.; Sun, K.; Kan, Z.; Lu, S.; et al. Crystallinity dictates the selection of fullerene or non-fullerene acceptors in a small molecule organic solar cell. Dyes Pigm. 2021, 187, 109085. [CrossRef]

94. Yu, P.; Feng, G.; Li, J.; Li, C.; Xu, Y.; Xiao, C.; Li, W. A selenophene substituted double-cable conjugated polymer enables efficient single-component organic solar cells. J. Mater. Chem. C 2020, 8, 2790-2797. [CrossRef]

95. Jiang, H.; Han, C.; Li, Y.; Bi, F.; Zheng, N.; Han, J.; Shen, W.; Wen, S.; Yang, C.; Yang, R.; et al. Rational Mutual Interactions in Ternary Systems Enable High-Performance Organic Solar Cells. Adv. Funct. Mater. 2020, 31, 2007088. [CrossRef]

96. Osaka, I.; Takimiya, K. Backbone orientation in semiconducting polymers. Polymer 2015, 59, A1-A15. [CrossRef]

97. Rogers, J.T.; Schmidt, K.; Toney, M.F.; Bazan, G.C.; Kramer, E.J. Time-resolved structural evolution of additive-processed bulk heterojunction solar cells. J. Am. Chem. Soc. 2012, 134, 2884-2887. [CrossRef]

98. Zhu, Q.; Xue, J.; Zhang, L.; Wen, J.; Lin, B.; Naveed, H.B.; Bi, Z.; Xin, J.; Zhao, H.; Zhao, C.; et al. Intermolecular Interaction Control Enables Co-optimization of Efficiency, Deformability, Mechanical and Thermal Stability of Stretchable Organic Solar Cells. Small 2021, 17, 2007011. [CrossRef]

99. Park, S.; Ahn, H.; Kim, J.-Y.; Park, J.B.; Kim, J.; Im, S.H.; Son, H.J. High-Performance and Stable Nonfullerene Acceptor-Based Organic Solar Cells for Indoor to Outdoor Light. ACS Energy Lett. 2019, 5, 170-179. [CrossRef]

100. Cui, Y.; Yao, H.; Zhang, T.; Hong, L.; Gao, B.; Xian, K.; Qin, J.; Hou, J. 1 cm² Organic Photovoltaic Cells for Indoor Application with over 20\% Efficiency. Adv. Mater. 2019, 31, 1904512. [CrossRef]

101. Lee, J.H.; You, Y.J.; Saeed, M.A.; Kim, S.H.; Choi, S.H.; Kim, S.; Lee, S.Y.; Park, J.S.; Shim, J.W. Undoped tin dioxide transparent electrodes for efficient and cost-effective indoor organic photovoltaics $\left(\mathrm{SnO}_{2}\right.$ electrode for indoor organic photovoltaics). NPG Asia Mater. 2021, 13, 43. [CrossRef]

102. Kim, S.H.; Saeed, M.A.; Lee, S.Y.; Shim, J.W. Investigating the Indoor Performance of Planar Heterojunction Based Organic Photovoltaics. IEEE J. Photovolt. 2021, 11, 997-1003. [CrossRef]

103. You, Y.J.; Song, C.E.; Hoang, Q.V.; Kang, Y.; Goo, J.S.; Ko, D.H.; Lee, J.J.; Shin, W.S.; Shim, J.W. Highly Efficient Indoor Organic Photovoltaics with Spectrally Matched Fluorinated Phenylene-Alkoxybenzothiadiazole-Based Wide Bandgap Polymers. Adv. Funct. Mater. 2019, 1901171. [CrossRef]

104. Sakata, T.; Kajiya, D.; Saitow, K.I. Brush Printing Creates Polarized Green Fluorescence: 3D Orientation Mapping and Stochastic Analysis of Conductive Polymer Films. ACS Appl. Mater. Interfaces 2020, 12, 46598-46608. [CrossRef]

105. Qu, G.; Park, K.S.; Kafle, P.; Zhang, F.; Kwok, J.J.; Patel, B.B.; Smilgies, D.-M.; Thomsen, L.; McNeill, C.R.; Diao, Y. Lyotropic Liquid Crystalline Mesophase Governs Interfacial Molecular Orientation of Conjugated Polymer Thin Films. Chem. Mater. 2020, 32, 6043-6054. [CrossRef]

106. Lee, Y.; Mongare, A.; Plant, A.; Ryu, D. Strain-Microstructure-Optoelectronic Inter-Relationship toward Engineering MechanoOptoelectronic Conjugated Polymer Thin Films. Polymers 2021, 13, 935. [CrossRef]

107. Spano, F.C. Modeling disorder in polymer aggregates: The optical spectroscopy of regioregular poly(3-hexylthiophene) thin films. J. Chem. Phys. 2005, 122, 234701. [CrossRef]

108. DeLongchamp, D.M.; Vogel, B.M.; Jung, Y.; Gurau, M.C.; Richter, C.A.; Kirillov, O.A.; Obrzut, J.; Fischer, D.A.; Sambasivan, S.; Richter, L.J.; et al. Variations in semiconducting polymer microstructure and hole mobility with spin-coating speed. Chem. Mater. 2005, 17, 5610-5612. [CrossRef]

109. Kitchen, B.; Awartani, O.; Kline, R.J.; McAfee, T.; Ade, H.; O'Connor, B.T. Tuning Open-Circuit Voltage in Organic Solar Cells with Molecular Orientation. ACS Appl. Mater. Interfaces 2015, 7, 13208-13216. [CrossRef]

110. Luhman, W.A.; Holmes, R.J. Investigation of Energy Transfer in Organic Photovoltaic Cells and Impact on Exciton Diffusion Length Measurements. Adv. Funct. Mater. 2011, 21, 764-771. [CrossRef]

111. Han, J.; Liang, Q.; Qu, Y.; Liu, J.; Han, Y. Morphology Control of Non-fullerene Blend Systems Based on Perylene. Acta Phys.-Chim. Sin. 2018, 34, 391-406. [CrossRef]

112. Ruderer, M.A.; Guo, S.; Meier, R.; Chiang, H.-Y.; Körstgens, V.; Wiedersich, J.; Perlich, J.; Roth, S.V.; Müller-Buschbaum, P. Solvent-Induced Morphology in Polymer-Based Systems for Organic Photovoltaics. Adv. Funct. Mater. 2011, 21, $3382-3391$. [CrossRef]

113. Schmidt-Hansberg, B.; Sanyal, M.; Klein, M.F.G.; Pfaff, M.; Schnabel, N.; Jaiser, S.; Vorobiev, A.; Muller, E.; Colsmann, A.; Scharfer, P.; et al. Moving through the Phase Diagram: Morphology Formation in Solution Cast Polymer-Fullerene Blend Films for Organic Solar Cells. ACS Nano 2011, 5, 8579-8590. [CrossRef]

114. Manley, E.F.; Strzalka, J.; Fauvell, T.J.; Jackson, N.E.; Leonardi, M.J.; Eastham, N.D.; Marks, T.J.; Chen, L.X. In Situ GIWAXS Analysis of Solvent and Additive Effects on PTB7 Thin Film Microstructure Evolution during Spin Coating. Adv. Mater. 2017, 29, 1703933. [CrossRef] 
115. Chen, H.; Tang, H.; Hu, D.; Xiao, Y.; Fu, J.; Lv, J.; Yu, Q.; Xiao, Z.; Lu, X.; Hu, H.; et al. Design of All-Small-Molecule Organic Solar Cells Approaching 14\% Efficiency via Isometric Terminal Alkyl Chain Engineering. Energies 2021, 14, 2505. [CrossRef]

116. Lee, H.; Park, C.; Sin, D.H.; Park, J.H.; Cho, K. Recent Advances in Morphology Optimization for Organic Photovoltaics. Adv. Mater. 2018, 30, 1800453. [CrossRef]

117. Ayzner, A.L.; Tassone, C.J.; Tolbert, S.H.; Schwartz, B.J. Reappraising the Need for Bulk Heterojunctions in Polymer-Fullerene Photovoltaics: The Role of Carrier Transport in All-Solution-Processed P3HT/PCBM Bilayer Solar Cells. J. Phys. Chem. C 2009, 113, 20050-20060. [CrossRef]

118. de Villers, B.T.; Tassone, C.J.; Tolbert, S.H.; Schwartz, B.J. Improving the Reproducibility of P3HT:PCBM Solar Cells by Controlling the PCBM/Cathode Interface. J. Phys. Chem. C 2009, 113, 18978-18982. [CrossRef]

119. Wang, Z.; Xu, M.; Li, Z.; Gao, Y.; Yang, L.; Zhang, D.; Shao, M. Intrinsically Stretchable Organic Solar Cells beyond $10 \%$ Power Conversion Efficiency Enabled by Transfer Printing Method. Adv. Funct. Mater. 2021, 31, 2103534. [CrossRef]

120. Yao, Y.; Hou, J.; Xu, Z.; Li, G.; Yang, Y. Effects of Solvent Mixtures on the Nanoscale Phase Separation in Polymer Solar Cells. Adv. Funct. Mater. 2008, 18, 1783-1789. [CrossRef] 